\title{
NIST Calibration Services for Hydrometers
}

NIST Special Publication 250-78
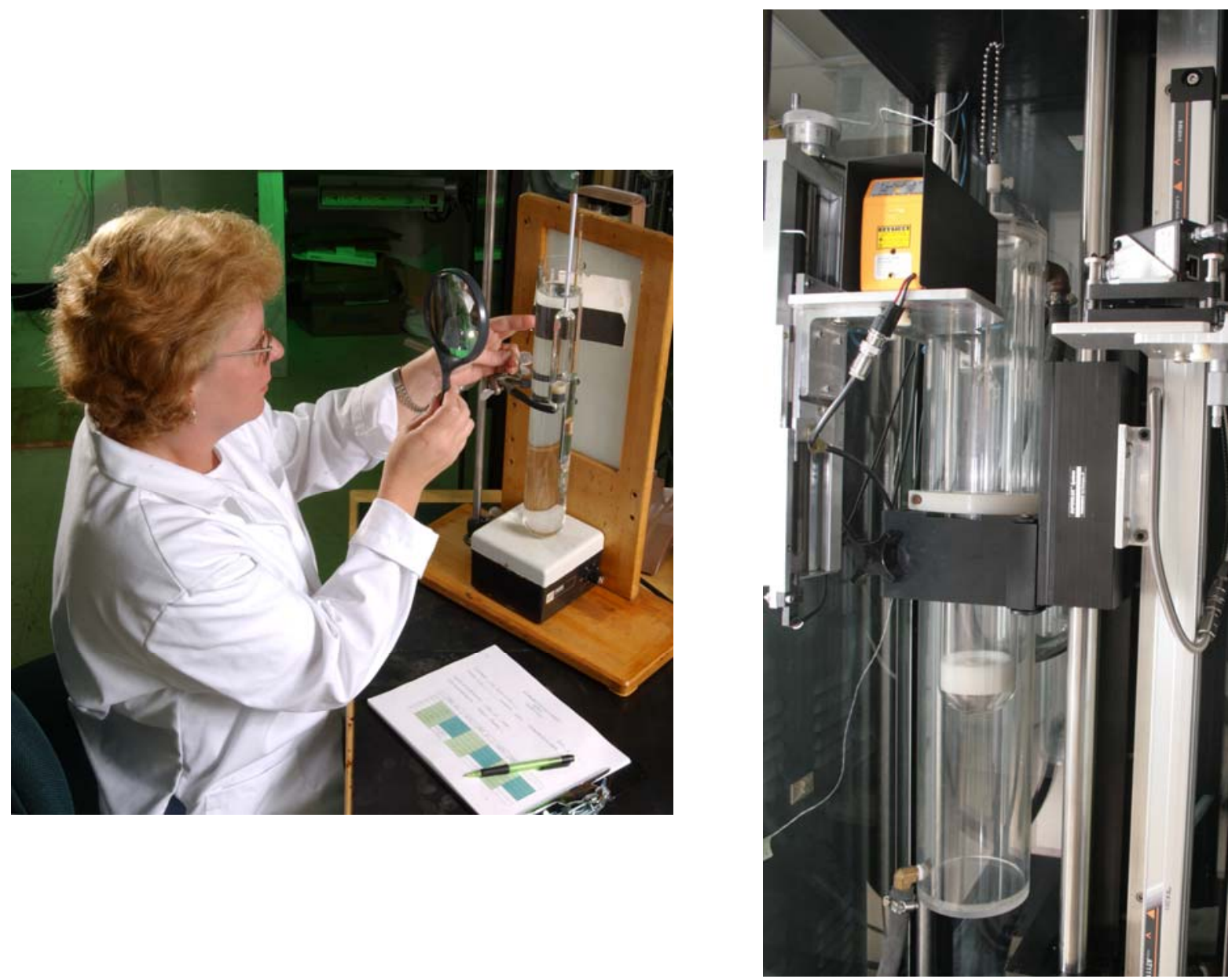

John. D. Wright, Vern E. Bean, Jesus Aguilera April 19, 2010

Fluid Metrology Group

Process Measurements Division

Chemical Science and Technology Laboratory National Institute of Standards and Technology Gaithersburg, Maryland, 20899 


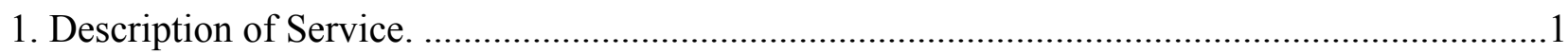

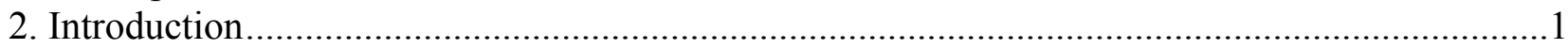

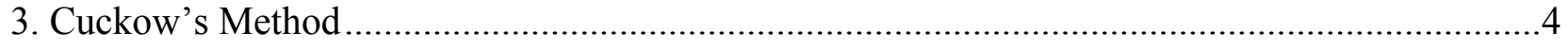

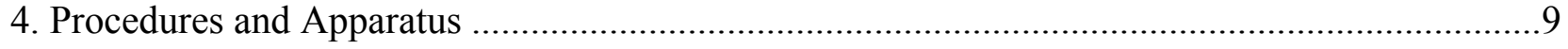

5. Surface Positioning Process ............................................................................................

6. Surface Tension and Contact Angle Effects ..............................................................................11

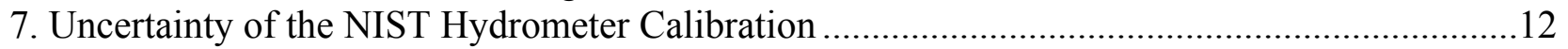

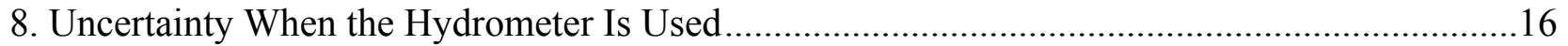

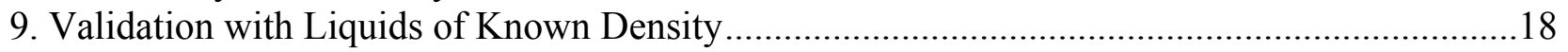

10. Comparison to NIST Historical Results for a Reference Hydrometer .....................................19

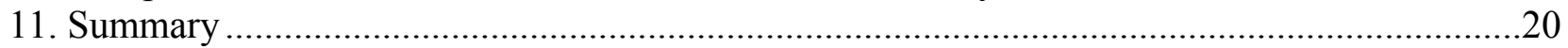

Appendix A. Corrections to Hydrometer Readings for Surface Tension Effects............................22 Appendix B: Corrections to Hydrometers for Temperature Effects ................................................2 Appendix C. Conversion of Liquid Density to Other Hydrometer Scales .....................................31

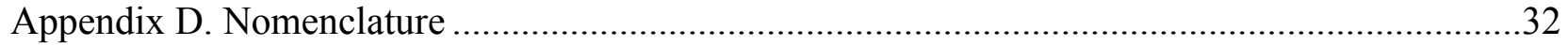

Appendix E. Sample Calibration Report...................................................................... 


\section{Description of Service.}

The National Institute of Standards and Technology (NIST) provides calibration services for hydrometers used to measure liquid density. Hydrometers with scales for density, specific gravity, proof spirit for alcohol solutions, API degrees for petroleum measurements, degrees Baume heavy and degrees Baume light, and others are accepted for calibration. NIST calibrations are done by weighing the hydrometer while it is immersed to specified scale markings in a liquid of known density (tridecane). Normally a calibration is done at three points, at approximately $10 \%, 50 \%$, and $90 \%$ of the scale. The calibration report includes a simple equation for each calibration point that gives the user a correction to the hydrometer reading that accounts for the surface tension of the liquid in which the hydrometer is used. The calibration results have an expanded uncertainty (with coverage factor of 2) of 100 parts in $10^{6}$ or less of the liquid density. The apparatus was validated by comparisons using liquids of known density: water, toluene, tridecane, and trichloroethylene. Results from these comparisons agreed within 40 parts in $10^{6}$ or less (see Table 3 ). The new calibration method is consistent with earlier, manual calibrations performed by NIST using reference hydrometers (see Figure 5).

Calibration customers should consult the web address http://ts.nist.gov/MeasurementServices/Calibrations/mechanical_index.cfm to find the most current information regarding our calibration service, calibration fees, technical contacts, turn around times, and instrument submittal procedures. The instructions for domestic customers have the sub-headings: A) Customer Inquiries,

B) Pre-arrangements and Scheduling,

C) Purchase Orders,

D) Shipping, Insurance, and Risk of Loss,

E) Turnaround Time

F) Customer Checklist.

There are also special instructions for foreign customers.

\section{Introduction}

A hydrometer is a simple and inexpensive instrument for measuring the density of liquids. The typical hydrometer... "is a glass instrument consisting of a bulb weighted at the lower end and surmounted by a stem, small in diameter compared with the bulb, in which is enclosed a scale on which readings are taken"'[1]. The instrument floats vertically in the liquid and the liquid density is measured by visually reading where the plane of the free surface of the liquid intersects the hydrometer scale (see Figure 1). Numerous standards documents are available that specify design and usage of hydrometers $[2,3,4,5]$.

Figure 1 illustrates the forces acting on a freely floating hydrometer. Two buoyant forces act in the upward direction, one due to the volume of the bulb and the portion of the stem below the

[1] Stott V 1938 Hydrometers, in The Science of Petroleum, ed A E Dunstan (London, Oxford University Press) vol III p 2322-7

[2] ISO 649-1 1981 Laboratory Glassware - Density Hydrometers for General Purposes - Specification.

[3] ISO 649-2 1981 Laboratory Glassware - Density Hydrometers for General Purposes - Test Methods and Use.

[4] ASTM E-100 2005 Standard Specification for ASTM Hydrometers, ASTM Standards 14.03.

[5] ASTM E-126 2005 Standard Test Method for Inspection and Verification of Hydrometers, ASTM

Standards 14.03. 
liquid surface that are displacing liquid, the other due to the portion of the stem that is displacing air. Gravity acts in the downward direction. In the hydrometer's equilibrium position, the upward and downward forces are balanced. The equilibrium position is mainly dependent on the density of the liquid. Hydrometer manufacturers position scales inside the hydrometer stem so that users can read the liquid density from the surface-scale intersection. Inevitably, there are small errors in the positioning of the scale and the density measurements can be improved by adding corrections to the hydrometer readings. This document describes the calibration procedure that applies Cuckow's method [6] to determine these hydrometer corrections.

Forces due to the liquid-vapor surface tension and the contact angle between the liquid-vapor interface and the hydrometer stem complicate hydrometer density measurements (see Figure 1). Most liquids partially or completely wet clean glass. For such liquids, a curved liquid-vapor interface (meniscus) rises up the hydrometer stem and, in effect, pulls the hydrometer deeper into the liquid. (A few liquids, e.g. mercury, do not wet clean glass. For such liquids, the meniscus is depressed below the free surface and surface tension pulls the hydrometer upwards.) When aqueous solutions contact a, clean, glass hydrometer, the rising meniscus can alter the hydrometer's equilibrium position by as much as a $0.2 \%$ reduction of the liquid's density. For hydrocarbon liquids the reduction of the apparent density can be as large as $0.1 \%$. Hence, for most hydrometer applications, it is necessary to account for surface tension effects in order to obtain the desired density accuracy. The NIST hydrometer calibration service provides hydrometer corrections that are a function of the surface tension of the customer's liquid assuming that the contact angle between the meniscus and the stem is zero. [see Section 3, Equation (10).] Appendix D is a sample calibration report.

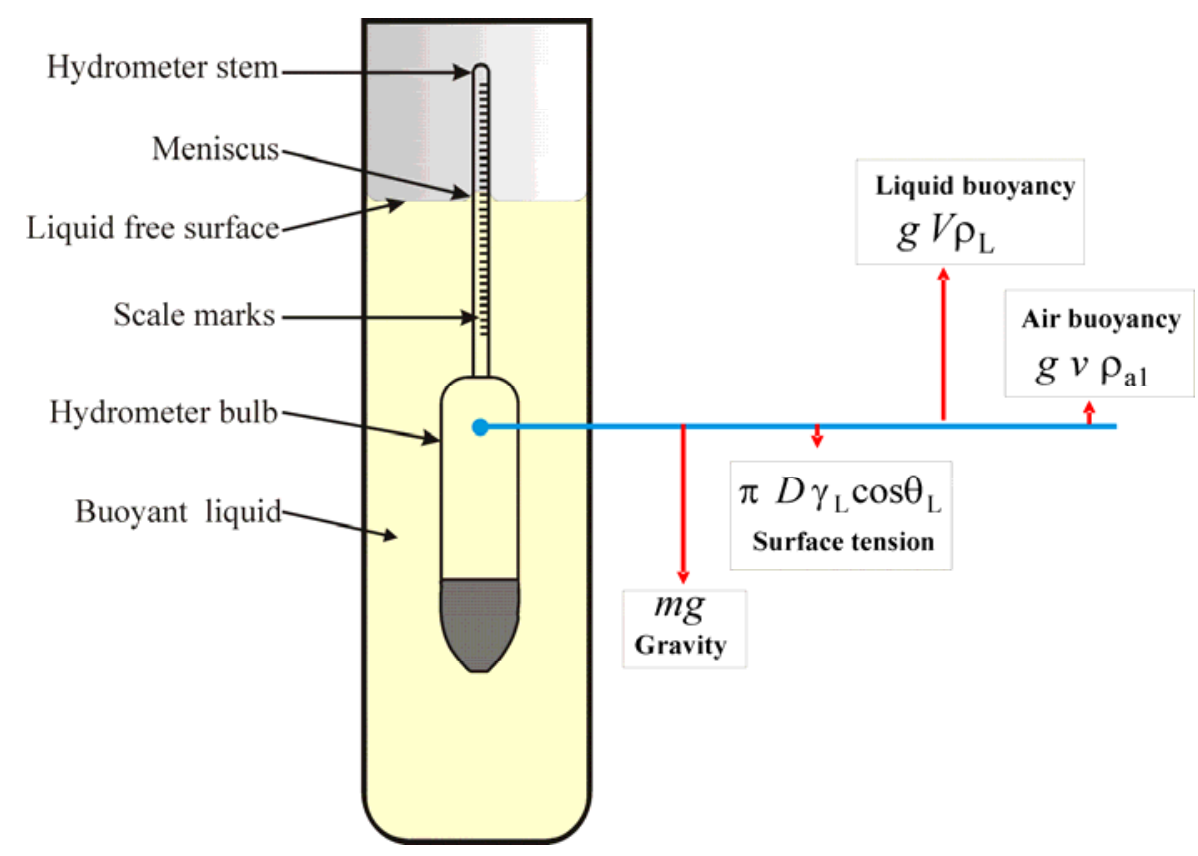

Figure 1. Schematic of a freely floating hydrometer with representations of the forces imposed on it. See Section 3 for nomenclature.

[6] Cuckow F W 1949 A New Method of High Accuracy for the Calibration of Reference Standard Hydrometers, J. Soc. Chem. Industry, 68, 44-9 
Although hydrometers with SI units of $\mathrm{g} / \mathrm{cm}^{3}$ are desirable today, for historical reasons a number of other hydrometer units prevail. In the United States, the most common unit for hydrometers is specific gravity, the density of the measured liquid at a reference temperature relative to the density of distilled water at a reference temperature (i.e. specific gravity $60^{\circ} \mathrm{F} / 60^{\circ} \mathrm{F}^{+}$). This unit was developed because distilled water was a convenient reference material.

Hydrometers can be used to measure any liquid property that is a function of density simply by putting an appropriate scale in the hydrometer stem. Examples are percentage of ethyl alcohol, sugar, or sulfuric acid in water. Other scales include the Baume scale used by the sugar industry, and the American Petroleum Institute or API scale used by the petroleum industry. Conversions between the various scales are discussed in the literature [7] and in Appendix A of this document.

There are two primary methods for calibrating hydrometers. One method requires floating the hydrometer in several liquids of different densities, which are determined by applying Archimedes' principle to a sinker of known mass and volume. The second method (Cuckow's method) requires hydrostatic weighing, i.e. using a balance to measure the apparent mass ${ }^{*}$ of the hydrometer while it is immersed to several levels in a single liquid of known density. Cuckow's method has many advantages. It eliminates the inconvenience of storing a collection of liquids, such as aqueous solutions of acids and mixtures of volatile hydrocarbons. It permits the calibration of a hydrometer at specified scale marks without the inconvenience of preparing liquid mixtures to specified densities. In addition, Cuckow's method can be automated more easily. In the apparatus described here, we use tridecane as the liquid of known density because of six attributes:

1) commercially available in high purity,

2) a stable density that is low enough to calibrate most hydrometers without a sinker,

3) low vapor pressure,

4) non-hydroscopic (i.e., does not absorb water vapor from air),

5) a low, stable surface tension in contact with air,

6) low toxicity.

National standards laboratories are interested in automating the calibration of hydrometers in order to reduce uncertainties and reduce the labor involved thereby reducing cost to the customer $[8,9,10]$. The Fluid Metrology Group of NIST designed and built an automated, primary standard apparatus for the calibration of hydrometers using Cuckow's method and began using it for customer calibrations in 2007. The NIST apparatus suspends the customer's hydrometer from a balance and immerses it far enough into tridecane so that the hydrometer mark to be calibrated

\footnotetext{
${ }^{+}$specific gravity $60^{\circ} \mathrm{F} / 60^{\circ} \mathrm{F}$ is not an SI unit, but is still a widely found on hydrometers used in the United States.

[7] Hughes J C 1954 Testing of Hydrometers, National Bureau of Standards Circular 555, (Gaithersburg, National Institute of Standards and Technology)

* Apparent mass is force divided by gravitational acceleration as measure by a balance.

[8] Jacques C 1999 Calibration of Hydrometers - Procedures, NRCC 42747, (Canada, National Research Council Canada)

[9] Lee Y J, Chang K H, and Oh C Y 2004 Automatic Alignment Method for Calibration of Hydrometers, Metrologia, 41, S100-S104

[10] Lorefice S and Malengo A 2006 Calibration of Hydrometers, Meas. Sci. Technol., 17, 2560-6
} 
is aligned with the free surface. The apparent mass of the hydrometer in this configuration is combined with its apparent mass in air to calculate the correction to the hydrometer scale as shown in Section 3. The automated NIST apparatus is shown schematically in Figure 2. The apparatus positions a horizontal laser light sheet on the hydrometer mark to be calibrated. Then it raises or lowers the thermostatted water bath until the free surface of the tridecane is aligned with the light sheet. A laser power meter indicates the correct alignment by a characteristic change in its reading. (See Section 5.)

The NIST apparatus achieves an expanded $(k=2)$ uncertainty of 100 parts in $10^{6}$ or less for the calibration results. Customers can expect larger uncertainties when they use their hydrometer for liquid density measurements due to the effects of surface tension, contact angle, improper reading of the meniscus, and temperature.
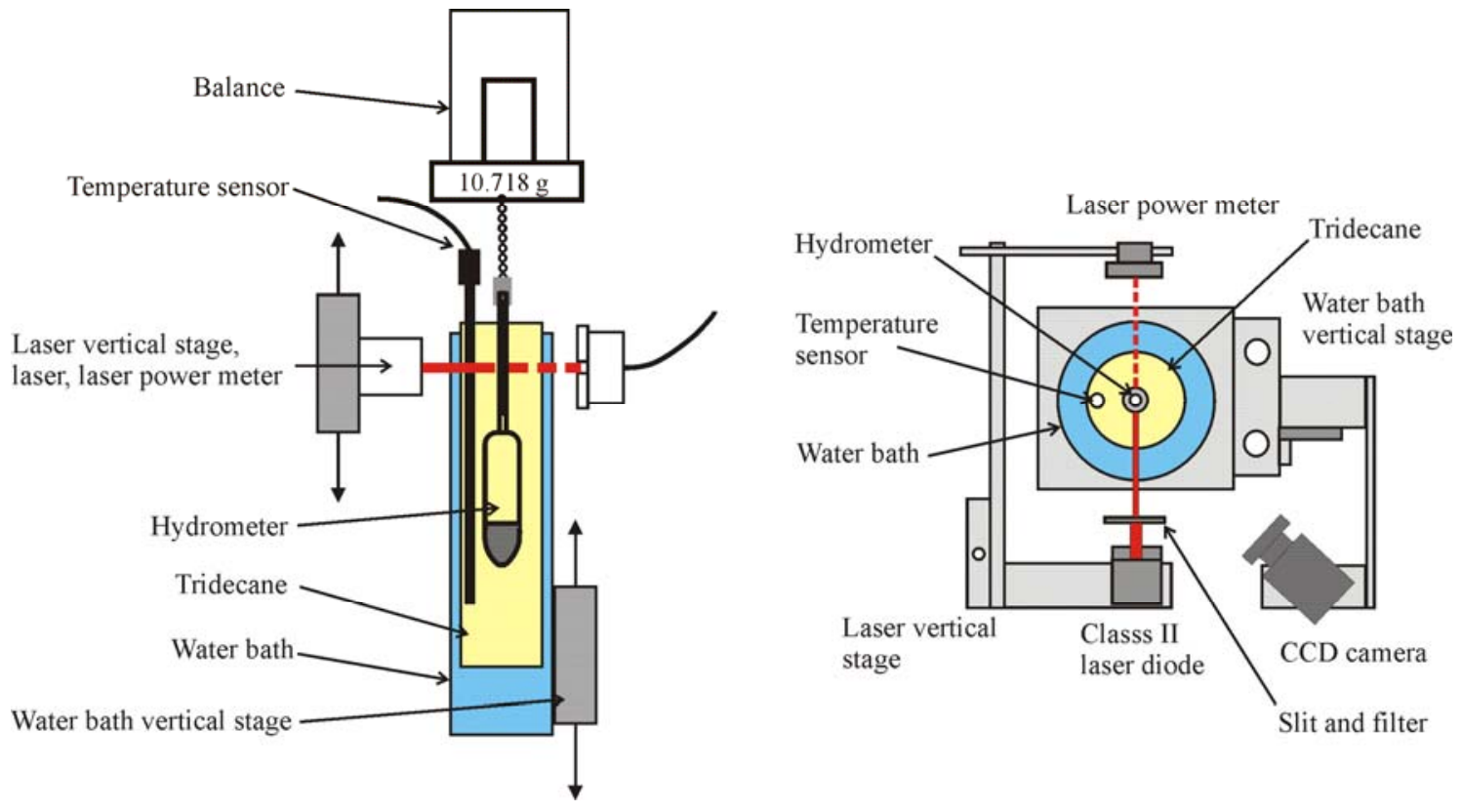

Figure 2. A schematic diagram of the NIST apparatus that applies Cuckow's method.

\section{Cuckow’s Method}

The development of the data reduction equation presented here follows the work of Cuckow [6]. The derivation uses the force balance equations for the hydrometer in three circumstances: 1, suspended from a balance in air, 2. freely floating at a particular mark in a liquid of known surface tension and unknown density (e.g. the customer's liquid), and 3, suspended at the same mark in another liquid of known density and surface tension (e.g. tridecane at NIST). The force balance equations are combined with the assumption that the density of the surrounding air is equal in all three cases to obtain corrections for any calibration mark on the hydrometer scale. The hydrometer is considered to be an instrument to measure liquid density, marked in units of $\mathrm{g} / \mathrm{cm}^{3}$, but corrections for other hydrometer scales can be determined as well.

We write an equation for the forces acting on a hydrometer for three cases:

1. floating freely in a liquid of density $\rho_{\mathrm{L}}$ at reference temperature $T_{0}$,

2. suspended from a balance in air, and 
3. suspended from a balance while immersed to the identical level as in Case 1, but in a liquid of known density $\rho_{\mathrm{T}}$ at temperature $T_{\mathrm{T}}$. (Tridecane is the liquid of known density, hence the subscript " $T$ ".) Note that $T_{\mathrm{T}}$ need not be equal to the hydrometer reference temperature $T_{0}$.

Solving the three equations simultaneously yields the data reduction equation.

Freely Floating: Assuming a rising meniscus, there are two downward forces acting on a hydrometer floating freely in a liquid: the force due to the surface tension of the liquid acting on the stem of the hydrometer and the force due to gravity. There are also two upward forces: the buoyant force due to the liquid displaced by the volume of the hydrometer below the liquid surface and the buoyant force of the air displaced by the volume of the hydrometer stem above the liquid surface. Equating the sum of upward forces to the sum of the downward forces, we have

$$
m g+\pi D \gamma_{\mathrm{L}} \cos \theta_{\mathrm{L}}=g V \rho_{\mathrm{L}}+g v \rho_{\mathrm{a} 1}
$$

where:

$m$ : mass of the hydrometer,

$g$ : local acceleration due to gravity,

$D$ : diameter of the hydrometer stem at the surface of the liquid,

$\gamma_{\mathrm{L}}:$ surface tension of the liquid in which the hydrometer is used,

$\theta_{\mathrm{L}}:$ contact angle of the liquid on the hydrometer stem,

$V$ : volume of the hydrometer below the liquid surface,

$\rho_{\mathrm{L}}$ : density of the liquid,

$v$ : volume of the hydrometer stem above the liquid surface, and

$\rho_{\mathrm{a} 1}$ : density of the air at the time the hydrometer scale was read.

For convenience, we introduce the symbol $\Gamma_{\mathrm{L}} \equiv \pi D \gamma_{\mathrm{L}} \cos \theta_{\mathrm{L}}$ for the surface tension force on the stem from the liquid.

Suspended from a Balance in Air: There are two forces acting on a hydrometer when it is suspended in air: the downward force due to gravity and the upward buoyant force due to the air displaced by the volume of the hydrometer. The reading of the balance, multiplied by $g$, is the sum of these two forces,

$$
g \alpha O_{2}=m g-g(V+v)\left[1+\beta\left(T_{2}-T_{0}\right)\right] \rho_{a 2}
$$

where:

$\alpha$ : calibration coefficient for the balance,

$\mathrm{O}_{2}$ : balance reading,

$\beta$ : volumetric thermal expansion coefficient of the glass from which the hydrometer is made,

$T_{2}$ : air temperature at the time of weighing in air,

$T_{0}$ : reference temperature (often it is $15.556{ }^{\circ} \mathrm{C}$ or $60^{\circ} \mathrm{F}$ ), and

$\rho_{\mathrm{a} 2}$ : air density at the time of weighing.

Suspended from a Balance While Partially Immersed: When the hydrometer is suspended while immersed in tridecane to the identical level as in the freely floating case, there are again two 
downward forces: that due to gravity and that due to surface tension acting on the stem of the hydrometer. There are also two upward forces: the buoyant force due to the tridecane displaced by the volume $V$ and the buoyant force due to the volume of air displaced by the volume $v$. The balance reading, multiplied by $g$, is the sum of all of these forces:

$$
g \alpha O_{3}=m g+\pi D \gamma_{\mathrm{T}} \cos \theta_{\mathrm{T}}-g V \rho_{\mathrm{T}}\left[1+\beta\left(T_{3}-T_{0}\right)\right]-g v \rho_{\mathrm{a} 3}
$$

where:

$O_{3}$ : balance reading,

$\gamma_{\mathrm{T}}:$ surface tension of tridecane,

$\theta_{\mathrm{T}}:$ contact angle of the tridecane on the hydrometer stem,

$T_{\mathrm{T}}:$ temperature of the tridecane,

$\rho_{\mathrm{T}}:$ density of the tridecane, and

$\rho_{\mathrm{a} 3}:$ density of the air at the time of the hydrostatic weighing in tridecane.

The buoyant force for the portion of the hydrometer stem in $\operatorname{air}\left[g v \rho_{\mathrm{a} 3} \beta\left(T_{\mathrm{T}}-T_{0}\right)\right]$ is negligibly small and has been dropped from Equation (3). For convenience, we introduce the symbol $\Gamma_{\mathrm{T}} \equiv \pi D \gamma_{\mathrm{T}} \cos \theta_{\mathrm{T}}$ for the surface tension force from tridecane.

Cuckow wrote: "The terms $v \rho_{\mathrm{a} 1}, v \rho_{\mathrm{a} 2}$, and $v \rho_{\mathrm{a} 3}$ in the three Equations (1), (2), and (3) represent the air buoyancies acting on the emergent stems of the hydrometer at various times. Variations in the density of the air surrounding the stems of hydrometers are neglected in normal hydrometry, the resultant changes in buoyant up thrust being too small to affect the hydrometer reading significantly. This procedure is equivalent to regarding terms of the form $v \rho_{\text {an }}$ as equal to a constant, say ' $k$ "'[6]. Thus Cuckow justifies the simplifying assumption,

$$
v \rho_{\mathrm{a} 1}=v \rho_{\mathrm{a} 2}=v \rho_{\mathrm{a} 3}=k
$$

We checked this approximation by deriving the data reduction equation without making the simplifying assumption. We did assume $\rho_{\mathrm{a} 2}=\rho_{\mathrm{a} 3}$ because both are measured during the hydrometer calibration. These measurements are separated by, at most, a few hours which normally results in negligibly small changes in air density. However, $\rho_{\mathrm{a} 1}$ will be measured by the hydrometer user at some other time and place, thus it might differ from $\rho_{\mathrm{a} 2}$ and $\rho_{\mathrm{a} 3}$ by as much as $20 \%$, the reduction in air density from NIST (altitude $100 \mathrm{~m}$ ) to an altitude of $2200 \mathrm{~m}$ [11]. Under these assumptions, we found Cuckow's approximation [Equation (4)] makes an error of less than 7 parts in $10^{6}$, which is negligible for most hydrometer measurements.

Data Reduction Equations: The steps to derive the data reduction equation are:

1. Substitute $k$ for $v \rho_{\mathrm{a} 1}, v \rho_{\mathrm{a} 2}$, and $v \rho_{\mathrm{a} 3}$ in Equations (1), (2), and (3).

2. Solve Equation 1 for $\rho_{\mathrm{L}}$. The result is,

[11] The altitude of Los Alamos National Laboratory is $2200 \mathrm{~m}$. Variations of air density as large as $3 \%$ result from weather. Jaeger, K. B., and Davis, R. S., A Primer for Mass Metrology, National Bureau of Standards (U.S.), NBS Special Publication 700-1, Industrial Measurement Series, 1984, 79 p. 


$$
\rho_{\mathrm{L}}=\frac{1}{V}\left(m-k+\frac{\Gamma_{\mathrm{L}}}{g}\right)
$$

3. Solve Equation (2) for $m-k$ and substitute it into Equation (5). The results are,

$$
\begin{gathered}
m-k=\alpha O_{2}+V \rho_{\mathrm{a} 2}\left[1+\beta\left(T_{2}-T_{0}\right)\right] \\
\rho_{\mathrm{L}}=\frac{1}{V}\left(\alpha O_{2}+\frac{\Gamma_{\mathrm{L}}}{g}\right)+\rho_{\mathrm{a} 2}
\end{gathered}
$$

where $\rho_{\mathrm{a} 2} \beta\left(T_{2}-T_{0}\right)$ is negligibly small and is not used.

4. Solve Equation (3) for $m-k$, substitute the result into Equation (6) and solve the resulting equation for $V$,

$$
V=\frac{\alpha\left(O_{2}-O_{3}\right)+\Gamma_{\mathrm{T}} / g}{\rho_{\mathrm{T}}\left[1+\beta\left(T_{\mathrm{T}}-T_{0}\right)\right]-\rho_{\mathrm{a} 2}}
$$

where $\rho_{\mathrm{a} 2} \beta\left(T_{\mathrm{T}}-T_{0}\right)$ is negligibly small and has been dropped.

5. Substitute Equation (8) into Equation (7) to obtain the final result,

$$
\rho_{\mathrm{L}}=\frac{\left\{\rho_{\mathrm{T}}\left[1+\beta\left(T_{\mathrm{T}}-T_{0}\right)\right]-\rho_{\mathrm{a} 2}\right\}\left(\alpha O_{2}+\Gamma_{\mathrm{L}} / g\right)}{\alpha\left(O_{2}-O_{3}\right)+\Gamma_{\mathrm{T}} / g}+\rho_{\mathrm{a} 2}
$$

When calibrating a hydrometer for use in liquids that are less dense than tridecane, a stainless steel weight is added to cause the hydrometer to sink. The weight is a ring of known mass and volume placed over the stem, resting on the top of the bulb. It is submerged in the tridecane during the hydrometer calibration. When the weight is used, Equation (3) must be modified to include the two forces acting on it: the force due to gravity and the buoyant force due to the tridecane it displaced. The modified equation is denoted as Equation (3').

$$
g \alpha O_{3}=m g+m_{\mathrm{s}} g+\Gamma_{\mathrm{T}}-g\left\{V\left[1+\beta\left(T_{\mathrm{T}}-T_{0}\right)\right]-V_{\mathrm{s}}\left[1+\beta_{\mathrm{s}}\left(T_{\mathrm{T}}-T_{0}\right)\right]\right\} \rho_{\mathrm{T}}-g v \rho_{\mathrm{a} 3}
$$

where:

$m_{\mathrm{s}}$ : mass of the stainless steel weight

$V_{\mathrm{s}}$ : volume of the stainless steel weight, and

$\beta_{\mathrm{s}}$ : volumetric thermal expansion coefficient of the stainless steel weight.

The data reduction equation when the stainless steel weight is used is,

$$
\rho_{\mathrm{L}}=\frac{\left\{\rho_{\mathrm{T}}\left[1+\beta\left(T_{\mathrm{T}}-T_{0}\right)\right]-\rho_{\mathrm{a} 2}\right\}\left(\alpha O_{2}+\Gamma_{\mathrm{L}} / g\right)}{\alpha O_{2}-\alpha O_{3}+\Gamma_{\mathrm{T}} / g+m_{\mathrm{s}}-V_{\mathrm{s}} \rho_{\mathrm{T}}\left[1+\beta_{\mathrm{s}}\left(T_{\mathrm{T}}-T_{0}\right)\right]}+\rho_{\mathrm{a} 2}
$$

The hydrometers most commonly calibrated at NIST are designed to measure specific gravity of a liquid at $60^{\circ} \mathrm{F}$ referenced to water at $60^{\circ} \mathrm{F}$ (a sp gr $60^{\circ} \mathrm{F} / 60^{\circ} \mathrm{F}$ hydrometer). For this situation, $T_{0}$ in Equation (9) or ( $\left.9^{\prime}\right)$ is set to $15.556^{\circ} \mathrm{C}\left(60^{\circ} \mathrm{F}\right)$ and $\rho_{\mathrm{L}}$ is divided by the density of distilled water at $T_{0}, 0.999016 \mathrm{~g} / \mathrm{cm}^{3}$ to obtain the true scale reading. 
Equations (9) and (9') include forces due to surface tension, those due to the calibration liquid (tridecane) as well as those due to the liquid in which the hydrometer is used by the customer. For liquids that wet glass, surface tension causes a meniscus to rise on the stem of a hydrometer and the force of the meniscus pulls the hydrometer deeper into the liquid, causing the hydrometer reading to be too low. Typically, surface tension forces on hydrometers effect density measurements by about $0.2 \%$ for aqueous solutions and about $0.1 \%$ for hydrocarbon liquids.

The hydrometer thermal expansion term in Equations (9) and (9') correct for differences in temperature between the calibration at NIST and the reference temperature of the hydrometer (the temperature at which the hydrometer is designed to be used).

NIST's balance is calibrated with stainless steel masses and it has an internal algorithm that assumes a nominal air density $\rho_{\mathrm{a} 2}$ so that the balance indicates a buoyancy-corrected mass. The force balances used to derive Equation (1) use the apparent mass (i.e., the indication of an ideal balance before buoyancy corrections are made). To obtain the apparent mass, the NIST balance readings $O_{2}$ and $O_{3}$ are multiplied by $\alpha=\left(1-\rho_{\mathrm{a} 2} / \rho_{\mathrm{s}}\right)=0.99985$ where $\rho_{\mathrm{s}}$ is the density of stainless steel calibration masses.

If desired by a calibration customer, NIST will report a value of, expressed in units specified, for each hydrometer scale mark that was calibrated where the value of $\rho_{\mathrm{L}}$ is based on a customer-provided value for the surface tension $\gamma_{\mathrm{L}}$ and the assumption that the contact angle $\theta_{\mathrm{L}}$ of the customer's liquid is zero when the calibrated hydrometer is used. Since the value of the customer's surface tension is not always known at the time of NIST's calibration (perhaps because the hydrometer will be applied in several liquids with different surface tensions) the result of the calibration is also reported as an equation that gives a correction to be added to each calibrated scale mark:

$$
C_{\mathrm{L}}=A+B \gamma_{\mathrm{L}} \cos \theta_{\mathrm{L}}
$$

where

$$
A=\frac{\left\{\rho_{\mathrm{T}}\left[1+\beta\left(T_{\mathrm{T}}-T_{0}\right)\right]-\rho_{\mathrm{a} 2}\right\} \alpha O_{2}}{\alpha O_{2}-\alpha O_{3}+\Gamma_{\mathrm{T}} / g+m_{\mathrm{s}}-V_{s}\left[1+\beta_{\mathrm{s}}\left(T_{\mathrm{T}}-T_{0}\right)\right] \rho_{\mathrm{T}}}+\rho_{\mathrm{a} 2}-R
$$

where $R$ is the hydrometer reading at the calibrated scale mark and

$$
B=\left(A+R-\rho_{\mathrm{a} 2}\right) \frac{\pi D}{\alpha O_{2} g}
$$

NIST calibration customers can use Equation (10) to calculate hydrometer corrections for a particular liquid under test. The values of $A$ and $B$ are the output of a NIST calibration. (See Appendix D for a sample report). In Section 7 of this paper, we will give the uncertainty contributed to $C_{\mathrm{L}}$ via $A$ and $B$. In Section 8 of this paper we will analyze the uncertainties that arise during usage of a hydrometer by a NIST calibration customer. For example, the values of surface tension and contact angle in Equation (10) depend on the liquid under test and the cleanliness of the hydrometer when it is used and are not included in the NIST calibration uncertainty. Surface tension effects are discussed in Section 6 and in Appendix B. 


\section{Procedures and Apparatus}

Each hydrometer is cleaned by a thorough rinse with ethanol and it is dried with a clean, paper towel before it is calibrated in tridecane by Cuckow's method.

Hydrometer calibration by Cuckow's method requires that the hydrometer be weighed in air and weighed while immersed to the selected scale marks in a liquid of known density, in our case, tridecane. In brief, the automated Cuckow's method procedures are:

1. Hang the hydrometer from a hook on the underside of the pan of the balance so that the stem intersects the free surface of the tridecane.

2. With the tridecane surface below the scale mark to be calibrated, center a horizontal sheet of laser light on that selected scale mark.

3. Raise the tridecane surface $3 \mathrm{~mm}$ above the scale mark and then lower it until the laser power meter mounted opposite the laser indicates a sharp decrease in the laser light intensity due to the tridecane surface being in the same plane as the scale mark to be calibrated (the "surface positioning process" shown in Figures 3 and 4).

4. Stop the travel of the tridecane surface, pause for the balance readings to stabilize, and record the tridecane temperature, the reading of the balance, and the reading of the encoder that monitors the travel of the tridecane surface.

The weighing of the hydrometer suspended in tridecane is done with an analytical balance located on top of a cabinet of square cross section, approximately $0.5 \mathrm{~m}$ on an edge and $1.5 \mathrm{~m}$ high (see Figure 2). The balance has a capacity of $205 \mathrm{~g}$ and a resolution of $0.0001 \mathrm{~g}$. The hydrometer is hung by a chain from the underside of the pan of the balance, which is centered over a hole in the top plate of the cabinet so as to be directly above the $100 \mathrm{~mm}$ diameter tube containing the tridecane. This tube is mounted vertically in a cylindrical, temperature controlled bath, which is mounted on a vertical stage such that the bath-and-tube can be raised and lowered by a motor under computer control. A linear encoder ( $5 \mu \mathrm{m}$ resolution) is attached to the vertical stage to monitor the position of the tridecane surface. Although the linear encoder measurements are not needed for density calculations, they are useful for calculating the repeatability of the surface positioning process. An external bath pumps temperature controlled water through the cylinder surrounding the tube of tridecane. A thermometer well mounted within the tridecane supports a calibrated thermistor to measure the temperature.

A CCD camera provides an image of the hydrometer scale on the computer monitor upon which cursors are placed to indicate the scale marks to be calibrated. A self-leveling class II laser (a laser diode mounted on a magnetically dampened pendulum) is located on its own vertical stage with a motor under computer control. The thickness of the laser light sheet $(0.2 \mathrm{~mm})$ is defined by a $50 \mathrm{~mm}$ long optical slit with a polarizing filter, located between the laser and the bath-andtube. A laser power meter is mounted on the opposite side of the bath-and-tube from the laser which detects when the tridecane surface and the scale mark to be calibrated are in the same plane by indicating a sharp decrease in the intensity of the laser light. The laser power meter output (in $\Omega$ ) is acquired by the computer and used along with the bath-and-tube vertical stage by the surface positioning process. A computer program controls the number of replications at each mark and then moves the entire process onto the next mark to be calibrated. The automated hydrometer calibrator is capable of applying Cuckow's method at any number of scale marks on the hydrometer scale without operator intervention. It will operate unattended overnight. 


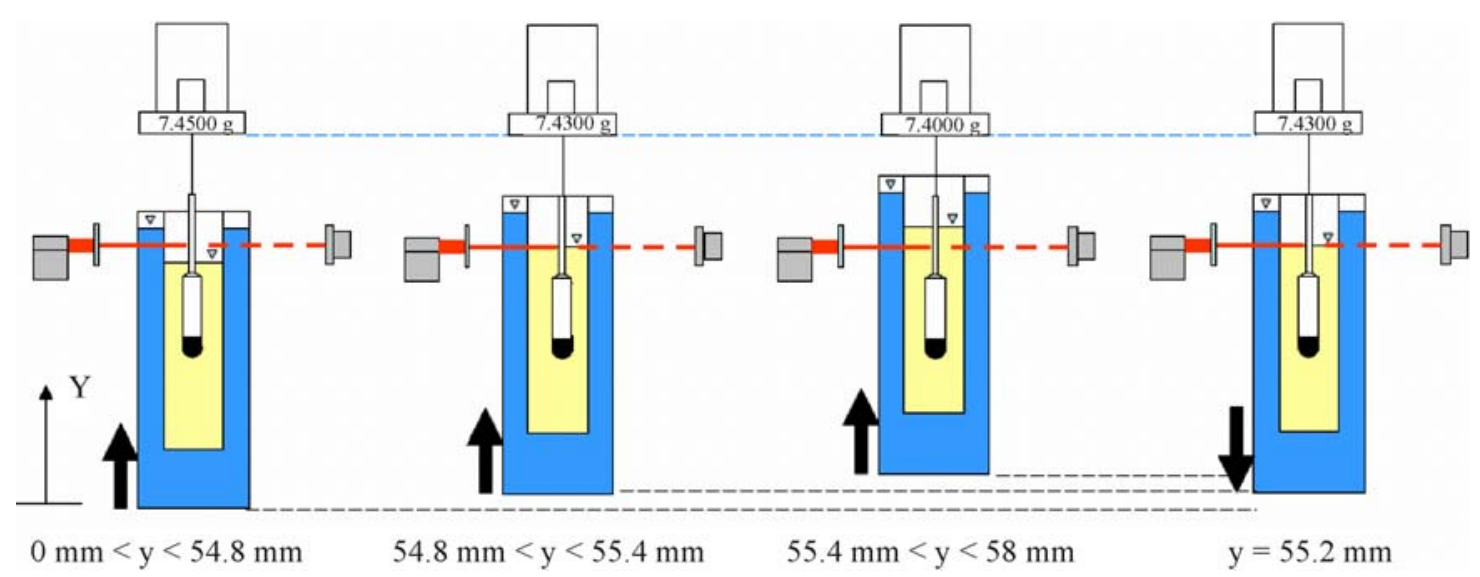

Figure 3. Surface positioning process

The apparatus can be operated in a semi-automatic mode wherein the operator centers the laser sheet on the scale mark to be calibrated by turning the lead screw by hand while looking directly at the scale or by looking at the CCD camera image of the scale on the computer monitor. Then the automatic features move the tridecane surface, determine when the tridecane surface is at the scale mark to be calibrated, and records the required data. The semi-automatic mode is faster than the fully automatic mode.

One of NIST's check standard hydrometers is calibrated immediately before each customer calibration. The tolerance of the check standard is $10^{-4}$ of the density. The check standard ensures that the entire calibration system (which includes the balance, the density of the tridecane, the surface tension of the tridecane, etc.) is operating within its expected range.

\section{Surface Positioning Process}

In the NIST apparatus, the laser light sheet is centered on the hydrometer scale mark to be calibrated and the tridecane surface is aligned with the center of the laser light sheet by lowering the tridecane and looking for the decrease in intensity of the laser light measured by the laser power meter. A plot of the laser light intensity versus elevation of the tridecane surface is shown in Figure 4. Figure 4 actually shows traces for three measurements at the same calibration mark to demonstrate the repeatability of the surface positioning process. The tridecane surface is raised above the mark to be calibrated by $3 \mathrm{~mm}$ and then lowered until the light intensity is at the half way point of the transition to ensure a stable and reproducible meniscus on the hydrometer stem. In Figure 4, at elevations from $51 \mathrm{~mm}$ to $54.8 \mathrm{~mm}$ the laser power meter outputs approximately $3000 \Omega$. At these elevations the laser sheet is passing through the walls of the tube and the bath, the water in the bath, and through air above the tridecane surface. At about $55 \mathrm{~mm}$ the light intensity moves through the transition and the power meter output rises from $3000 \Omega$ to $4500 \Omega$. At tridecane elevations of $55.4 \mathrm{~mm}$ and above, the power meter registers the highest intensity $(4500 \Omega)$. At these elevations the laser sheet is passing through the container walls, the water, and the tridecane. The three traces for the descending surface end at an elevation of about 55.2 where the surface positioning process has determined that the light intensity is at the midpoint of the transition. At this point the tridecane surface is aligned with the scale mark to be calibrated and after a $40 \mathrm{~s}$ wait for stabilization of the balance, its readings along with the tridecane temperature are recorded to a computer data file for later processing. The vertical stage changing the tridecane surface elevation is operated at a slow speed $(0.5 \mathrm{~mm} / \mathrm{min})$ so that the 
surface does not over run the desired position due to computer processing or actuation delays.

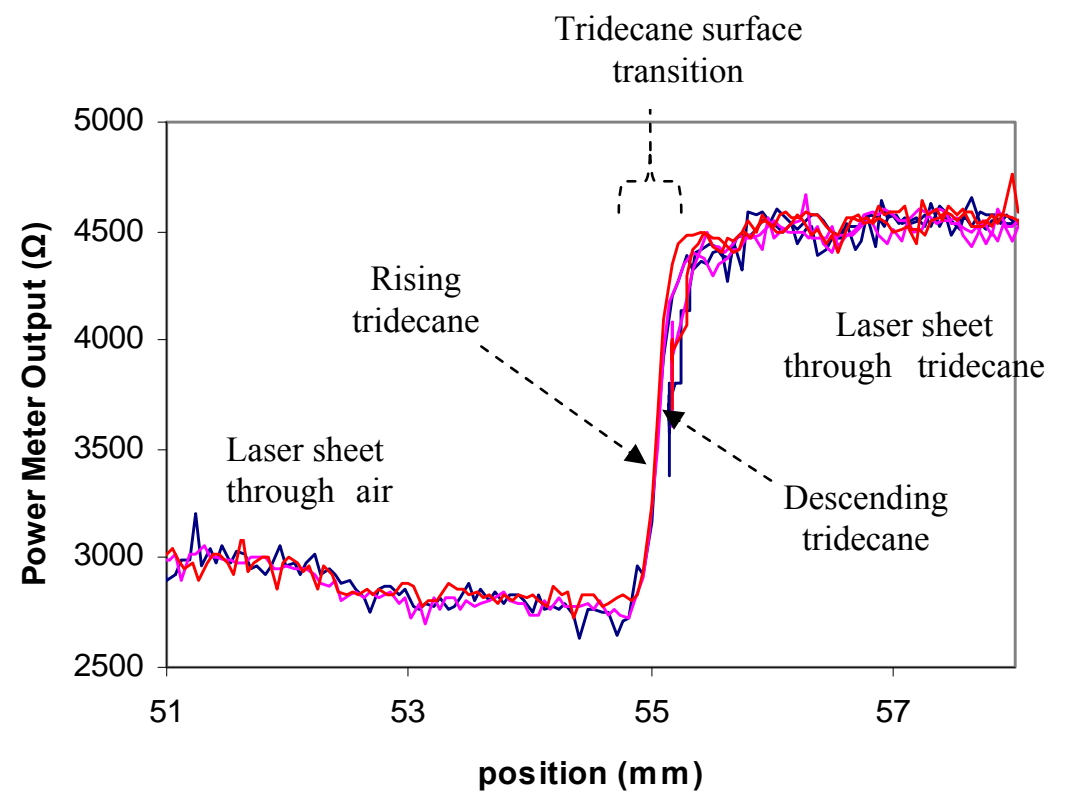

Figure 4. Laser power meter output versus the elevation of the liquid tridecane surface. As the liquid surface traverses the laser light sheet, the power meter registers the transition that we use in the surface positioning process.

The shape of the light intensity transition is caused by 1) the lens behavior of the tridecane filled cylinder, 2) the vertical intensity profile of the laser light sheet, and 3) refraction and reflection of the light sheet by the tridecane meniscus. The large change in intensity is due to the vessel of tridecane acting as a cylindrical lens, focusing the light onto the power meter window. The width of the transition (about $0.2 \mathrm{~mm}$ ) is due to the width of the laser light sheet. As the tridecane is raised and a larger portion of the light sheet passes through the liquid lens, the power meter readings increase. Therefore, at the midpoint of the transition, the middle of the laser light sheet is aligned with the bottom of the meniscus. Since we align the middle of the light sheet with the hydrometer mark to be calibrated, the bottom of the meniscus is aligned with the hydrometer mark to be calibrated.

The decrease in intensity seen between $51 \mathrm{~mm}$ and $55 \mathrm{~mm}$ in Figure 4 is caused by refraction and reflection of the laser light by the tridecane meniscus inside the cylinder. The angle formed by the tridecane at the cylinder wall refracts or reflects (depending on the angle of the meniscus surface) the laser light away from the power meter window. The hysteresis in the power meter output between the rising versus descending tridecane surface is caused by the non-zero contact angle on the cylinder and hydrometer.

\section{Surface Tension and Contact Angle Effects}

Surface tension and contact angle effects are the primary reason for our selecting tridecane as the liquid of known density. The surface tension of tridecane is $25 \mathrm{mN} / \mathrm{m}$ at $20{ }^{\circ} \mathrm{C}$. This is approximately $1 / 3$ of the surface tension of water at $20^{\circ} \mathrm{C}$, consequently, surface tension and contact angle effects are approximately $1 / 3$ of those for water. The surface tension of tridecane (and hydrocarbon liquids in general) has a weak sensitivity to contaminants. We found that the 
contact angle measured by the sessile drop method is effectively zero following a simple rinse with ethanol and drying with a clean paper towel.

Initially we used distilled water as the liquid of known density in our apparatus. We had difficulty obtaining reliable results due to the sensitivity of water's surface tension and contact angle to contaminants on the water's surface or on the hydrometer stem. Water has large surface tension, $73 \mathrm{mN} / \mathrm{m}$ at $20^{\circ} \mathrm{C}$; however, trace contamination by detergents or hydrocarbons will reduce its surface tension by as much as $10 \mathrm{mN} / \mathrm{m}$. An error in surface tension of $10 \mathrm{mN} / \mathrm{m}$ leads to errors of 150 parts in $10^{6}$ for $1 \mathrm{~g} / \mathrm{cm}^{3}$ hydrometer.

The contact angle formed by the water with the glass hydrometer stem is also sensitive to contamination that leads to unreliable results. The force due to surface tension on the glass hydrometer stem is $\pi D \gamma \cos \theta$ where $\theta$ is the contact angle of the liquid with the hydrometer stem [12]. Derivations of the equations for Cuckow's method generally assume that the contact angle is exactly zero, so that the surface tension force is $\pi D \gamma$. This assumption is made because it is particularly difficult to measure the contact angle against a curved surface such as a hydrometer stem and because the stem is assumed to be cleaned well enough that the contact angle is effectively zero. However, we have found that many glass cleaning procedures do not result in an effectively zero contact angle and that even if the stem is clean, it will not remain clean enough over a period of hours in our laboratory. In particular, glass cleaned with solvents, finished with ethanol, and air dried does not achieve an effectively zero contact angle. We note that if a hydrometer is cleaned with chromic-sulfuric acid, rinsed with water, air dried, and used immediately, the contact angle is less than $10^{\circ}$, which is close enough to zero. However, the stem will not remain clean for long unless carefully protected from contamination, such as oil droplets in air.

\section{Uncertainty of the NIST Hydrometer Calibration}

We analyzed the uncertainty of a density measurement caused by the NIST hydrometer calibration results $[A$ and $B$ in Equation (2)] following the method of propagation of uncertainties $[13,14,15]$. This involved obtaining normalized sensitivity coefficients, $S_{\mathrm{i}}=\left(1 / \rho_{\mathrm{L}}\right)\left(\partial \rho_{\mathrm{L}} / \partial x_{\mathrm{i}}\right)$, by partial differentiation. We also obtained standard uncertainties $\left(\mathrm{d} x_{\mathrm{i}}\right)$ for the calibration inputs from experiments with the instruments in the apparatus. We examined a number of cases and found that the calibration results from our apparatus normally have an expanded uncertainty (coverage factor $k=2$ ) of 100 parts in $10^{6}$ or less. In the following section, we consider uncertainty components that arise during application of the hydrometer (temperature effects, the customer's surface tension and contact angle) and find that they can lead to uncertainties of 370 parts in $10^{6}(k=2)$, or larger.

[12] Adamson A W and Gast A P 1997 Physical Chemistry of Surfaces, $6^{\text {th }}$ ed., (New York, John Wiley and Sons)

[13] International Organization for Standardization 1996 Guide to the Expression of Uncertainty in Measurement, (Switzerland, International Organization for Standardization)

[14] Taylor B N and Kuyatt C E 1994 Guidelines for Evaluating and Expressing the Uncertainty of NIST Measurement Results, NIST Technical Note 1297, (Gaithersburg, National Institute of Standards and Technology)

[15] Coleman H W and Steele W G 1999 Experimentation and Uncertainty Analysis for Engineers, $2^{\text {nd }}$ ed (New York, John Wiley and Sons) 
Table 1 gives an uncertainty analysis for a hydrometer that we used to measure the density of water. This hydrometer is similar in design to those that we receive for calibration. It has a span of $0.05 \mathrm{~g} / \mathrm{cm}^{3}$ and each scale increment is $1.3 \mathrm{~mm}$ long and represents $0.0005 \mathrm{~g} / \mathrm{cm}^{3}$. The uncertainty analysis in Table 1 includes only the components related to the calibration at NIST using NIST apparatus. Table 1 has columns for: 1) the input quantities to Equation (1), 2) symbols $x_{\mathrm{i}}$ for each input quantity, 3$)$ their values, 4) the values of the standard uncertainties $(k=$ $1), 5$ ) the units for each quantity, 6) the normalized sensitivity coefficients, 7) the values for the sensitivity coefficients, and 8) the product of the normalized sensitivity coefficient and the standard uncertainty, expressed as parts in $10^{6}$. The following numbered paragraphs correspond to the numbered $k=1$ uncertainty components listed in Table 1 and explain their origin.

1. We measured the density of the tridecane used in our apparatus by applying Arcimedes' principle to a spherical stainless steel sinker of known mass and known volume at temperatures between $15{ }^{\circ} \mathrm{C}$ and $23^{\circ} \mathrm{C}$. The standard uncertainty of the Archimedes apparatus is 5 parts in $10^{6}$. The standard deviation of the density data from a linear function of the temperature was 2 parts in $10^{6}$. The uncertainty of the temperature of the tridecane in the hydrometer calibration apparatus is $0.008 \mathrm{~K}$. This contributes to the tridecane density uncertainty through the thermal expansion coefficient $\beta_{\mathrm{T}}=710 \times 10^{-6} \mathrm{~K}^{-1}$. Taking the RSS of the components listed above gives a standard uncertainty of the tridecane density of $7 \times 10^{-6}$ $\mathrm{g} / \mathrm{cm}^{3}$ or 9 parts in $10^{6}$. (We also checked the tridecane density using a vibrating tube densimeter that had been calibrated with air and distilled water. The densimeter results agreed with the Archimedes' apparatus results within 37 parts in $10^{6}$, within the uncertainty of the densimeter.)

2. Hydrometers are made from a variety of glasses, including borosilicate glass and soda-lime glass. The volumetric thermal expansion coefficient of these glasses varies from $9 \times 10^{-6} \mathrm{~K}^{-1}$ to $26 \times 10^{-6} \mathrm{~K}^{-1}$. Unless a reliable value is specified, this component has a relatively large standard uncertainty and contributes significantly to the expanded uncertainty of the NIST calibration. This component can be reduced to negligible levels by operating the apparatus at the hydrometer reference temperature. In this example we have operated the apparatus at $20^{\circ} \mathrm{C}$ and used a reference temperature of $15.56^{\circ} \mathrm{C}\left(60^{\circ} \mathrm{F}\right)$ to illustrate that the component is significant (22 parts in $10^{6}$ here).

3. The temperature of the tridecane was spatially surveyed and monitored with a thermister. The tridecane temperature within the tube was uniform within $0.003 \mathrm{~K}$ and stable within $0.005 \mathrm{~K}$ during the 3 hour interval necessary to calibrate a hydrometer. The results of three annual calibrations of this thermister are consistent within $0.005 \mathrm{~K}$. The root-sum-square (RSS) of these temperature components is $0.008 \mathrm{~K}$; we will use this value as the standard uncertainty of the temperature of the tridecane.

5. and 6. Zero drift of the balance is the primary source of uncertainty for the apparent masss measurement $(0.3 \mathrm{mg})$. Zero readings are checked before and after hydrometer calibrations and zero readings in error by more than $3 \mathrm{mg}$ trigger re-testing. Repeatability, resolution $(0.1$ $\mathrm{mg}$ ), linearity (checked periodically with calibration masses), and the uncertainty of calibration masses are negligible in comparison. For the dry hydrometer measurement, the balance's resolution and linearity are the most significant components and the standard uncertainty is $0.15 \mathrm{mg}$. 
Table 1. Uncertainty analysis for a hydrometer calibrated with the NIST Cuckow's apparatus. See Table 2 for extra components that arise during hydrometer usage.

\begin{tabular}{|c|c|c|c|c|c|c|c|}
\hline Quantity & $x_{\mathrm{i}}$ & $\begin{array}{c}x_{\mathrm{i}} \\
\text { Value }\end{array}$ & $\begin{array}{l}\mathrm{d} x_{\mathrm{i}} \\
\text { Value }\end{array}$ & units & $S_{\mathrm{i}}$ & $\begin{array}{c}S_{\mathrm{i}} \\
\text { Value }\end{array}$ & $\begin{array}{c}10^{6} S_{\mathrm{i}} \\
\mathrm{d} x_{\mathrm{i}}\end{array}$ \\
\hline $\begin{array}{l}\text { 1) Density of } \\
\text { tridecane }\end{array}$ & $\rho_{\mathrm{T}}$ & 0.756 & $7 \times 10^{-6}$ & $\mathrm{~g} / \mathrm{cm}^{3}$ & $\frac{O_{2}-O_{3}+m_{\mathrm{s}}}{\rho_{\mathrm{T}}\left(O_{2}-O_{3}+m_{\mathrm{s}}-\rho_{\mathrm{T}} V_{\mathrm{s}}\right)}$ & 1.32 & 9 \\
\hline $\begin{array}{l}\text { 2) Hydrometer } \\
\text { volume thermal } \\
\text { expansion }\end{array}$ & $\beta$ & $2.5 \times 10^{-5}$ & $5 \times 10^{-6}$ & $1 / K$ & $T_{\mathrm{T}}-T_{0}$ & 4.44 & 22 \\
\hline $\begin{array}{l}\text { 3) Temperature of } \\
\text { tridecane }\end{array}$ & $T_{\mathrm{T}}$ & 20.0 & 0.008 & ${ }^{\circ} \mathrm{C}$ & $\frac{\beta\left(O_{2}-O_{3}+m_{\mathrm{s}}-\rho_{\mathrm{T}} V_{\mathrm{s}}\right)+\beta_{\mathrm{s}} V_{\mathrm{s}} \rho_{\mathrm{T}}}{O_{2}-O_{3}+m_{\mathrm{s}}-V_{\mathrm{s}} \rho_{\mathrm{T}}}$ & $2.5 \times 10^{-5}$ & 0 \\
\hline 4) Density of air & $\rho_{\mathrm{a} 2}$ & $1.2 \times 10^{-3}$ & $1 \times 10^{-5}$ & $\mathrm{~g} / \mathrm{cm}^{3}$ & $\frac{-O_{3}+m_{\mathrm{s}}-\rho_{\mathrm{T}} V_{\mathrm{s}}}{\rho_{\mathrm{T}} O_{2}}$ & -0.32 & -3 \\
\hline $\begin{array}{l}\text { 5) Hydrometer } \\
\text { apparent mass } \\
\text { in air }\end{array}$ & $\mathrm{O}_{2}$ & 48 & 0.00015 & $\mathrm{~g}$ & $\frac{-O_{3}+m_{\mathrm{s}}-\rho_{\mathrm{T}} V_{\mathrm{s}}}{O_{2}\left(O_{2}-O_{3}+m_{\mathrm{s}}-\rho_{\mathrm{T}} V_{\mathrm{s}}\right)}$ & $-6.6 \times 10^{-3}$ & -1 \\
\hline $\begin{array}{l}\text { 6) Hydrometer } \\
\text { apparent mass } \\
\text { in tridecane }\end{array}$ & $\mathrm{O}_{3}$ & 11.6 & 0.0003 & $\mathrm{~g}$ & $\frac{1}{O_{2}-O_{3}+m_{\mathrm{s}}-\rho_{\mathrm{T}} V_{\mathrm{s}}}$ & $2.8 \times 10^{-2}$ & 8 \\
\hline 7) Stem diameter & $D$ & 0.5 & 0.001 & $\mathrm{~cm}$ & $\frac{\pi}{g}\left[\frac{\gamma_{\mathrm{L}} \cos \left(\theta_{\mathrm{L}}\right)}{O_{2}}-\frac{\gamma_{\mathrm{T}} \cos \left(\theta_{\mathrm{T}}\right)}{O_{2}-O_{3}+m_{\mathrm{s}}-\rho_{\mathrm{T}} V_{\mathrm{s}}}\right]$ & $-2.3 \times 10^{-3}$ & 2 \\
\hline $\begin{array}{l}\text { 8) Surface tension } \\
\text { of tridecane }\end{array}$ & $\gamma_{\mathrm{T}}$ & 25 & 0.5 & $\mathrm{mN} / \mathrm{m}$ & $-\frac{\pi D \cos \left(\theta_{\mathrm{T}}\right)}{g\left(O_{2}-O_{3}+m_{s}-\rho_{T} V_{s}\right)}$ & $-4.4 \times 10^{-5}$ & -22 \\
\hline $\begin{array}{l}\text { 9) Contact angle } \\
\text { in tridecane }\end{array}$ & $\cos \left(\theta_{\mathrm{T}}\right)$ & 1 & 0.015 & & $-\frac{\pi D \gamma_{\mathrm{T}}}{g\left(O_{2}-O_{3}+m_{s}-\rho_{T} V_{s}\right)}$ & $-1.1 \times 10^{-3}$ & -17 \\
\hline $\begin{array}{l}\text { 10) Acceleration } \\
\text { due to gravity }\end{array}$ & $g$ & 980 & $1 \times 10^{-2}$ & $\mathrm{~cm} / \mathrm{s}^{2}$ & $\frac{\pi D}{g^{2}}\left[\frac{\gamma_{\mathrm{L}} \cos \left(\theta_{\mathrm{L}}\right)}{O_{2}}-\frac{\gamma_{\mathrm{T}} \cos \left(\theta_{\mathrm{T}}\right)}{O_{2}-O_{3}+m_{\mathrm{s}}-\rho_{\mathrm{T}} V_{\mathrm{s}}}\right]$ & $-1.2 \times 10^{-6}$ & 0 \\
\hline 11) Mass of sinker & $m_{\mathrm{s}}$ & 0 & $0^{*}$ & g & $\frac{-1}{O_{2}-O_{3}+m_{\mathrm{s}}-\rho_{\mathrm{T}} V_{\mathrm{s}}}$ & $-2.8 \times 10^{-2}$ & 0 \\
\hline $\begin{array}{l}\text { 12) Volume of } \\
\text { sinker }\end{array}$ & $V_{\mathrm{s}}$ & 0 & $0^{*}$ & $\mathrm{~cm}^{3}$ & $\frac{1}{O_{2}-O_{3}+m_{\mathrm{s}}-\rho_{\mathrm{T}} V_{\mathrm{s}}}$ & $2.8 \times 10^{-2}$ & 0 \\
\hline $\begin{array}{l}\text { 13) Thermal } \\
\text { expansion of } \\
\text { sinker volume }\end{array}$ & $\beta_{\mathrm{s}}$ & 0 & $0^{*}$ & $1 / \mathrm{K}$ & $\frac{\rho_{\mathrm{T}} V_{\mathrm{s}}\left(T_{\mathrm{T}}-T_{0}\right)}{O_{2}-O_{3}+m_{\mathrm{s}}-\rho_{\mathrm{T}} V_{\mathrm{s}}}$ & 0.74 & 0 \\
\hline $\begin{array}{l}\text { 14) Laser } \\
\text { positioning }\end{array}$ & & & $8.3 \times 10^{-3}$ & $\mathrm{~cm}$ & $\frac{1}{\rho_{\mathrm{L}}} \frac{\partial \rho_{\mathrm{L}}}{\partial \ell}$ & $3.7 \times 10^{-3}$ & 31 \\
\hline $\begin{array}{l}\text { 15) Surface } \\
\text { positioning }\end{array}$ & & & $2 \times 10^{-3}$ & $\mathrm{~cm}$ & $\frac{1}{\rho_{\mathrm{L}}} \frac{\partial \rho_{\mathrm{L}}}{\partial \ell}$ & $3.7 \times 10^{-3}$ & 7 \\
\hline 16) Repeatability & & 1 & $1 \times 10^{-5}$ & $\mathrm{~g} / \mathrm{cm}^{3}$ & & 1 & 10 \\
\hline \multicolumn{6}{|c|}{ Expanded Uncertainty of NIST Calibration } & RSS x 2 & 101 \\
\hline
\end{tabular}

${ }^{*}$ Sinker not used for the hydrometer used in this example. 
8. We measured the surface tension of our tridecane with a DuNouy tensiometer and our measurements differed from literature values [16] by $1 \mathrm{mN} / \mathrm{m}$ or less. We have taken $0.5 \mathrm{mN} / \mathrm{m}$ as the standard uncertainty.

9. Our experiments showed that the contact angle for tridecane-air interface on glass is small after the glass is rinsed in ethanol and dried with a paper towel. Our calculations assume the contact angle is zero, but we will use a standard uncertainty of $10^{\circ}$ for our uncertainty analysis. It is convenient to express the uncertainty in terms of $\cos \left(\theta_{\mathrm{T}}\right)$ and $\cos \left(\theta_{\mathrm{L}}\right)$ rather than $\theta_{\mathrm{T}}$ and $\theta_{\mathrm{L}}$.

10. The acceleration of gravity $g$ at the apparatus is $980.1018 \mathrm{~cm} / \mathrm{s}^{2}$ with a standard uncertainty of 10 parts in $10^{6}$ or less. [17]

11. , 12., and 13. The sinker is needed only when calibrating hydrometers for liquids less dense than tridecane $\left(<0.76 \mathrm{~g} / \mathrm{cm}^{3}\right)$. When the sinker is used, the sinker uncertainty components are all less than 6 parts in $10^{6}$, which is negligible compared to other components.

14. The largest uncertainty component is one that is not explicitly found in Equation (1): the alignment of the laser light sheet with the hydrometer stem mark. The uncertainty for this component depends on the pixel resolution of the camera system that we use during alignment. The standard uncertainty is one half of the pixel dimension $(0.016 / 2=0.08 \mathrm{~mm})$. The normalized sensitivity coefficient for this component is $\left(1 / \rho_{\mathrm{L}}\right)\left(\partial \rho_{\mathrm{L}} / \partial \ell\right)$ where $\ell$ is the length along the hydrometer stem. For a hydrometer of the design used in this example $\left(1.3 \mathrm{~mm}\right.$ scale increments represent $\left.0.0005 \mathrm{~g} / \mathrm{cm}^{3}\right), 0.08 \mathrm{~mm}$ length uncertainty corresponds to 31 parts in $10^{6}$ density uncertainty. This uncertainty value is not changed when the laser is aligned with the scale mark by the operator instead of by the computer. We have calibrated the same stem mark repeatedly, manually moving the laser light sheet off and back onto the mark each time, and we have found the standard deviation of the calibration results to be 20 parts in $10^{6}$.

15. We also include a component due to alignment of the tridecane surface with the laser light sheet by the surface positioning process. The process reliably locates the midpoint of the power meter transition within $10 \%$ of the transition. The slope of the transition (see Figure 4) allows us to translate the $10 \%$ uncertainty into a length and then a density uncertainty for the hydrometer stem design ( 7 parts in $10^{6}$ ). This value is confirmed by repeatability measurements: when we leave the laser light sheet in a fixed position and use the surface positioning process repeatedly, the liquid surface position (as measured by the linear encoder) has a standard deviation of $0.016 \mathrm{~mm}, 6$ parts in $10^{6}$ for density.

16. All of the uncertainty components discussed up to now are of type B. For a customer calibration, we include the standard deviation of repeated measurements made at the same scale mark in the uncertainty analysis (type A). In our experience, this is always less than 10 parts in $10^{6}$ and we have included a component of this size in Table 1.

Taking the root-sum-square of the components and multiplying by 2 gives an expanded, approximately $95 \%$ confidence level uncertainty. The result is 101 parts in $10^{6}(k=2)$ for a hydrometer of the design type we calibrate most often.

[16] Jasper J J, Kerr E R, and Gregorich F 1953 The Orthobaric Surface Tensions and Thermodynamic Properties of the Liquid Surfaces of the n-Alkanes, $C_{5}$ to $C_{28}$, J Am Chem Soc, 75, 5252-5254

[17] Tate D R 1967 Acceleration Due to Gravity at the National Bureau of Standards, J. of Res. of the National Bureau of Standards-C, Engineering and Instrumentation, 72C, No. 1 
In this example, the laser positioning component is the largest contributor. This component is analogous to the ability to "read" the position of the liquid surface on the hydrometer scale and we can do this with our apparatus with standard uncertainty of $0.08 \mathrm{~mm}$. This length corresponds to different density uncertainties depending on the design of the hydrometer under test. For a high resolution hydrometer, this component can drop to less than half the value in Table 1 . Then, the dominant uncertainty components of our apparatus become surface tension, contact angle, and the hydrometer thermal expansion coefficient, and the expanded uncertainty of the calibration result falls below 100 parts in $10^{6}(k=2)$.

\section{Uncertainty When the Hydrometer Is Used}

Table 2 shows uncertainty analyses for hydrometers used to measure the density of water and two hydrocarbon liquids (trichloroethylene and toluene). The table gives sample magnitudes for illustration, but users' values may be quite different. The examples are given to show hydrometer users that uncertainties other than the NIST calibration must be considered and that those extra uncertainties are significant.

Surface tension and contact angle are needed when Equations (1) or (2) are used to calculate the density of a liquid. The uncertainty of these values is dependent on the liquid under test. For hydrocarbon liquids, handbook surface tension values are available and uncertainties of $1 \mathrm{mN} / \mathrm{m}$ are reasonable. Simple cleaning procedures will give contact angles of nearly zero with standard uncertainty of $10^{\circ}$ for hydrocarbons on glass. For water and aqueous solutions, only certain cleaning procedures will give contact angles less than $20^{\circ}$ (for instance chromic-sulfuric acid, water rinsed, air dried) and unless these procedures are used, large uncertainties must be assumed. This problem is compounded by the large values of surface tension for aqueous solutions and their large uncertainties since they are sensitive to contamination.

Uncertainty due to thermometer calibration and temperature non-uniformity of the liquid sample in which the hydrometer is floated can be large. The sensitivity coefficient is proportional to the volumetric thermal expansion coefficient of the liquid under test, about $200 \times 10^{-6} \mathrm{~K}^{-1}$ for aqueous solutions, about $1000 \times 10^{-6} \mathrm{~K}^{-1}$ for most hydrocarbons, and $1670 \times 10^{-6} \mathrm{~K}^{-1}$ for trichloroethylene. The temperature uncertainty used in Table 2 is half the measurement resolution recommended in an ISO hydrometer procedure and one tenth of the allowed difference between before and after temperature measurements [18].

[18] International Organization for Standardization 1981 ISO 649/2 Laboratory Glassware - Density Hydrometers for General Purposes - Part 2: Test Methods and Use, (Switzerland, International Organization for Standardization) 
Table 2. Uncertainty for hydrometer density measurements in water, trichloroethylene, and toluene.

\begin{tabular}{|c|c|c|c|c|c|c|c|c|c|c|c|c|c|c|c|}
\hline $\begin{array}{l}\text { Liquid } \\
\text { under test }\end{array}$ & & & & \multicolumn{4}{|c|}{ Water } & \multicolumn{4}{|c|}{ Trichloroethylene } & \multicolumn{4}{|c|}{ Toluene } \\
\hline Quantity & $x_{\mathrm{i}}$ & units & $S_{\mathrm{i}}$ & $x_{\mathrm{i}}$ & $\mathrm{d} x_{\mathrm{i}}$ & $S_{\mathrm{i}}$ & $\begin{array}{l}10^{6} \times \\
S_{\mathrm{i}} \mathrm{d} x_{\mathrm{i}}\end{array}$ & $x_{\mathrm{i}}$ & $\mathrm{d} x_{\mathrm{i}}$ & $S_{\mathrm{i}}$ & $\begin{array}{l}10^{6} \times \\
S_{\mathrm{i}} \mathrm{d} x_{\mathrm{i}}\end{array}$ & $x_{\mathrm{i}}$ & $\mathrm{d} x_{\mathrm{i}}$ & $S_{\mathrm{i}}$ & $\begin{array}{l}10^{6} \times \\
S_{\mathrm{i}} \mathrm{d} x_{\mathrm{i}}\end{array}$ \\
\hline $\begin{array}{l}\text { NIST } \\
\text { calibration }\end{array}$ & $A, B$ & & & & & 1 & 50 & & & 1 & 44 & & & 1 & 39 \\
\hline $\begin{array}{l}\text { User } \\
\text { surface } \\
\text { tension }\end{array}$ & $\gamma_{\mathrm{L}}$ & $\begin{array}{c}\mathrm{mN} / \\
\mathrm{m}\end{array}$ & $\frac{\pi D \cos \left(\theta_{\mathrm{L}}\right)}{g O_{2}}$ & 68 & 2.5 & $3.1 \times 10^{-5}$ & 78 & 29 & 1 & $3.1 \times 10^{-5}$ & 17 & 28 & 1 & $2.7 \times 10^{-5}$ & 27 \\
\hline $\begin{array}{l}\text { User } \\
\text { contact } \\
\text { angle }\end{array}$ & $\cos \left(\theta_{\mathrm{L}}\right)$ & & $\frac{\pi D \gamma_{\mathrm{L}}}{g O_{2}}$ & 0.94 & 0.045 & $2.3 \times 10^{-3}$ & -102 & 1 & 0.015 & $5 \times 10^{-4}$ & 8 & 1 & 0.015 & $5 \times 10^{-4}$ & 12 \\
\hline$T$ effects & $T_{\mathrm{L}}$ & ${ }^{\circ} \mathrm{C}$ & $\frac{1}{\rho_{\mathrm{L}}} \frac{\partial \rho_{\mathrm{L}}}{\partial \ell}$ & 20 & 0.1 & $2 \times 10^{-4}$ & 20 & 20 & 0.1 & $1.7 \times 10^{-3}$ & 167 & 20 & 0.1 & $9 \times 10^{-4}$ & 92 \\
\hline Resolution & $\rho_{\mathrm{L}}$ & $\mathrm{g} / \mathrm{cm}$ & & 1.0 & $1 \times 10^{-4}$ & & 100 & 1.46 & $1 \times 10^{-4}$ & & 68 & 0.87 & $5 \times 10^{-5}$ & & 58 \\
\hline $\begin{array}{l}\text { Expanded } \\
\text { Usage }\end{array}$ & certain & of $\mathrm{Hy}$ & ometer & & & RSS $\times 2$ & 344 & & & RSS $\times 2$ & 373 & & & RSS $\times 2$ & 238 \\
\hline
\end{tabular}


Two additional uncertainty components deserve mention: the density of air and the gravitational constant. Cuckow's derivation assumes that the air density buoying the emergent stem is equal during calibration and usage. We examined the case where a hydrometer was calibrated at sea level and used at an elevation of $2000 \mathrm{~m}$ and found that Cuckow's approximation introduced an error of less than 10 parts in $10^{6}$, negligible relative to the uncertainties in Table 2 . We also note that the two instances of $g$ found in Equation (1) may differ since calibration and usage may occur at different latitudes or altitudes. A difference in $g$ of $0.25 \%$ leads to an error of less than 10 parts in $10^{6}$.

For water, the dominant uncertainty contributors are the surface tension and contact angle. For trichloroethylene, temperature effects dominate all others due to a large thermal expansion coefficient. In the example for a hydrometer used in toluene, the hydrometer scale has twice the resolution of the prior examples. This allows lower uncertainty from our apparatus (77 parts in $\left.10^{6}, k=2\right)$ and during usage (238 parts in $\left.10^{6}, k=2\right)$.

\section{Validation with Liquids of Known Density}

The performance of the apparatus was validated with a two step process. First we freely floated a hydrometer in a liquid of known density. We stirred the liquid, measured its temperature, floated the hydrometer and read it by eye, removed the hydrometer, stirred the liquid, and measured the temperature of the liquid again. We then used our apparatus and Equation (1) to calculate the density represented by the same stem scale mark read on the freely floating hydrometer. We performed the validation tests in four liquids; tridecane, toluene, water, and trichloroethylene. The results of the validation tests are listed in Table 3 . The densities based on temperature measurements and from the Cuckow's apparatus all agree within $0.00003 \mathrm{~g} / \mathrm{cm}^{3}$ (40 parts in $\left.10^{6}\right)$

Table 3. Summary of validation tests using liquids of known density.

\begin{tabular}{ccccc}
\hline Liquid & $\begin{array}{c}\text { Density from } \\
\text { equation of state } \\
\left(\mathrm{g} / \mathrm{cm}^{3}\right)\end{array}$ & $\begin{array}{c}\text { Density from } \\
\text { Cuckow's } \\
\text { apparatus } \\
\left(\mathrm{g} / \mathrm{cm}^{3}\right)\end{array}$ & $\begin{array}{c}\text { Difference } \\
\left(\mathrm{g} / \mathrm{cm}^{3}\right)\end{array}$ & $\begin{array}{c}\text { Difference } \\
\left(\text { parts in } 10^{6}\right)\end{array}$ \\
\hline Tridecane & 0.75695 & 0.75692 & -0.00003 & -40 \\
Toluene & 0.86779 & 0.86778 & -0.00001 & -12 \\
Water & 0.99825 & 0.99824 & -0.00001 & -10 \\
Trichloroethylene & 1.46550 & 1.46551 & +0.00001 & +6 \\
\hline
\end{tabular}

The density as a function of temperature (at atmospheric pressure) for tridecane and trichloroethylene were determined by Archimedes' principle as described earlier (standard uncertainty 5 parts in $10^{6}$ ). (The same tridecane was used for the freely floating measurements and the Cuckow's apparatus measurements). The density as a function of temperature for the toluene sample was measured with a vibrating tube densimeter (standard uncertainty 15 parts in $\left.10^{6}\right)$. The density of the water was calculated using the equation of Patterson and Morris [1]. We

[1] Patterson J B and Morris E C 1994 Measurement of Absolute Water Density, $1{ }^{\circ} \mathrm{C}$ to $40{ }^{\circ} \mathrm{C}$, Metrologia, 
compared the Archimedes' apparatus and vibrating tube densimeter measurements of the density of our distilled water to the equation of Patterson and Morris and found agreement within 10 parts in $10^{6}$. Therefore the standard uncertainty of the density as a function of temperature equations for the liquids used in the validation experiments is always less than 15 parts in $10^{6}$.

The validation experiments apply hydrometers in much the same way that our calibration customers do. As a result, the validation experiments are subject to the same uncertainty concerns for the freely floating test that are listed in Tables 2 and 3, i.e., the Cuckow's apparatus results, surface tension, contact angle, temperature, and resolution, as well as the density as a function of temperature uncertainties given above. We used chromic sulfuric acid to clean the hydrometer stems for the freely floating experiments and this is critical to obtaining low uncertainty for the water validation experiment. The density agreement found in the validation experiments (40 parts in $10^{6}$ ) is well within our expectations based on an uncertainty analysis (373 parts in $10^{6}$ ) for the experiment.

\section{Comparison to NIST Historical Results for a Reference Hydrometer}

NIST has a collection of reference hydrometers that have been used to calibrate customers' hydrometers by the comparison method. The reference hydrometers have been calibrated by placing them in liquids of known density, said density determined by measuring the apparent mass of sinkers of known mass and volume (Archimedes' principle). We have records of the calibration of one of these reference hydrometers (KNEK 260) by Bowman and Gallagher [2] (measured in 1956, published in 1969). We calibrated KNEK 260 in our Cuckow's apparatus at three different tridecane temperatures and the results, along with those of Bowman and Gallagher are shown in Figure 5. The old and new calibrations agree within 160 parts in $10^{6}$ over the range of density tested.

The three sets of data from our apparatus differ by as much as 40 parts in $10^{6}$, and appear to be a function of test temperature. We believe the apparent temperature dependence is due to a small error in the value $\beta=23 \times 10^{-6} / \mathrm{K}$. that Bowman and Gallagher used for the volumetric thermal expansion coefficient of the KNEK 260 hydrometer. If we replace the Bowman and Gallagher value of $\beta$ with the value $\beta=19 \times 10^{-6} / \mathrm{K}$, the temperature dependence vanishes.

$31,277-88$

[2] Gallagher W H and Bowman H A 1969 An Improved High-Precision Calibration Procedure for Reference Standard Hydrometers, J. of Res. of the National Bureau of Standards-C, Engineering and Instrumentation, 73C, Nos. 3 and 4 


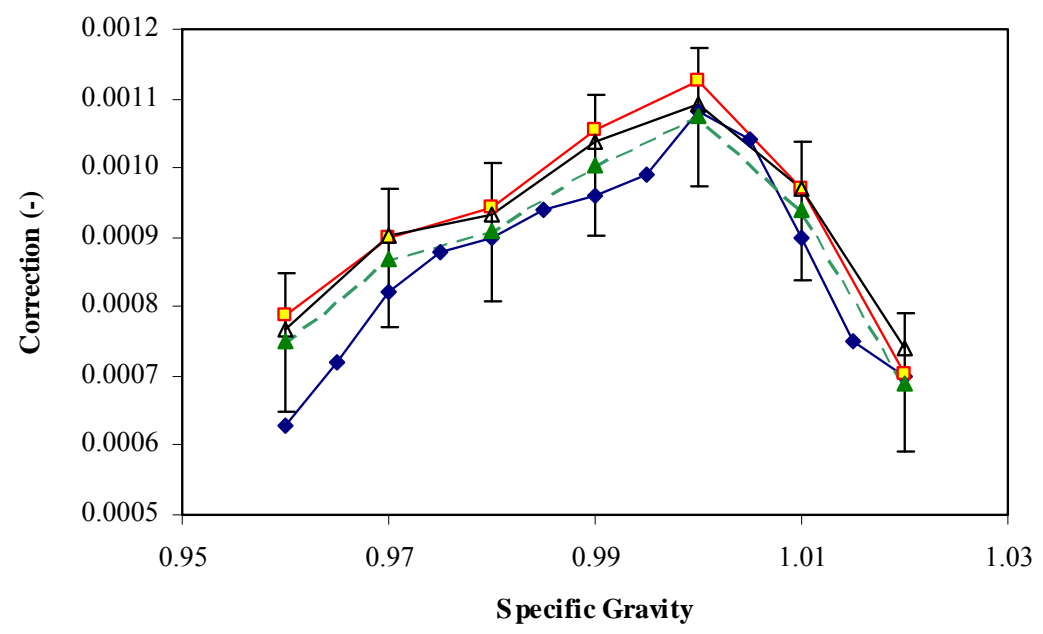

$$
\begin{aligned}
& \longrightarrow \text { Bowman \& Gallagher, } 1969 \\
& -\square \text { This work } 25^{\circ} \mathrm{C} \\
& -\square-\text { This work } 19^{\circ} \mathrm{C} \\
& \square-\text { This work } 16^{\circ} \mathrm{C}
\end{aligned}
$$

Figure 5. Corrections for hydrometer KNEK 260 from our apparatus (used at three tridecane temperatures) and from Bowman and Gallagher, 1969. Uncertainty bars are 100 parts in $10^{6}$ from Table 1.

\section{Summary}

We constructed and validated an automated standard that calibrates hydrometers by Cuckow's method. The advantages of the automated hydrometer calibrator include:

1. It can calibrate any number of hydrometer scale marks with any number of replications while unattended by an operator. Thus a hydrometer can be calibrated overnight.

2. Any location on the hydrometer scale can be calibrated. This is superior to the comparison method of calibration where the location on the scale of the calibration is dictated by the density of the liquid used for the calibration.

3. Only one calibrating fluid is used and it is user-friendly. In the comparison method, several mixtures of sulfuric acid/water and volatile organic solvent/oil mixtures are required.

Calibration results from the new standard will be presented in the format of Equation (10). To obtain the best results, customers must know the surface tension of the test liquid. Ignoring the surface tension term completely (i.e., assuming $B \gamma_{\mathrm{L}} \cos \theta_{\mathrm{L}}=0$ ) will lead to errors of about $0.002 \mathrm{~g} / \mathrm{cm}^{3}$ for aqueous solutions and about $0.001 \mathrm{~g} / \mathrm{cm}^{3}$ for hydrocarbon liquids. Handbook values are available for many liquids and the NIST Fluid Metrology Group can assist customers that need help determining the surface tension of the liquid they are working with.

We selected tridecane as the liquid of known density in our Cuckow's apparatus since it has relatively low surface tension $(25 \mathrm{~N} / \mathrm{m})$ that is not sensitive to contamination, and it forms a contact angle less than $10^{\circ}$ with the glass hydrometer stem even with a simple ethanol cleaning process. It has a low vapor pressure, so we do not lose liquid due to evaporation at an unacceptable rate. It is a single component fluid of high purity: the liquid that remains will maintain a constant density as some of it evaporates. 
The uncertainty of the calibration at NIST is 100 parts in $10^{6}$ for a typical hydrometer design. Usage of a hydrometer to measure an unknown liquid density introduces several significant uncertainty components (surface tension, contact angle, temperature effects, and resolution) that lead to uncertainties of 370 parts in $10^{6}$ or more unless great care is taken. This is particularly true for aqueous solutions or liquids with large thermal expansion coefficients.

We validated our automated Cuckow's apparatus using four liquids of known density and found agreement of 40 parts in $10^{6}$ or less, well within our uncertainty specifications. We compared the results of our apparatus with historic calibrations of one of our reference hydrometers (KNEK 260). KNEK 260 is one of the hydrometers we use as a working standard to perform comparison method calibrations of customer hydrometers. We found that the old and new calibrations agree within 160 parts in $10^{6}$, indicating that changing to our new calibration method should not introduce any significant discontinuity in the results of calibrations performed by NIST. We tested KNEK 260 at tridecane temperatures ranging from $16^{\circ} \mathrm{C}$ to $25^{\circ} \mathrm{C}$ and obtained consistent results within our uncertainty for the thermal expansion coefficient of the hydrometer. 


\section{Appendix A. Corrections to Hydrometer Readings for Surface Tension Effects}

A hydrometer floating in a liquid is subject to the forces shown in Figure A1: liquid buoyancy, air buoyancy, gravity, and surface tension effects.

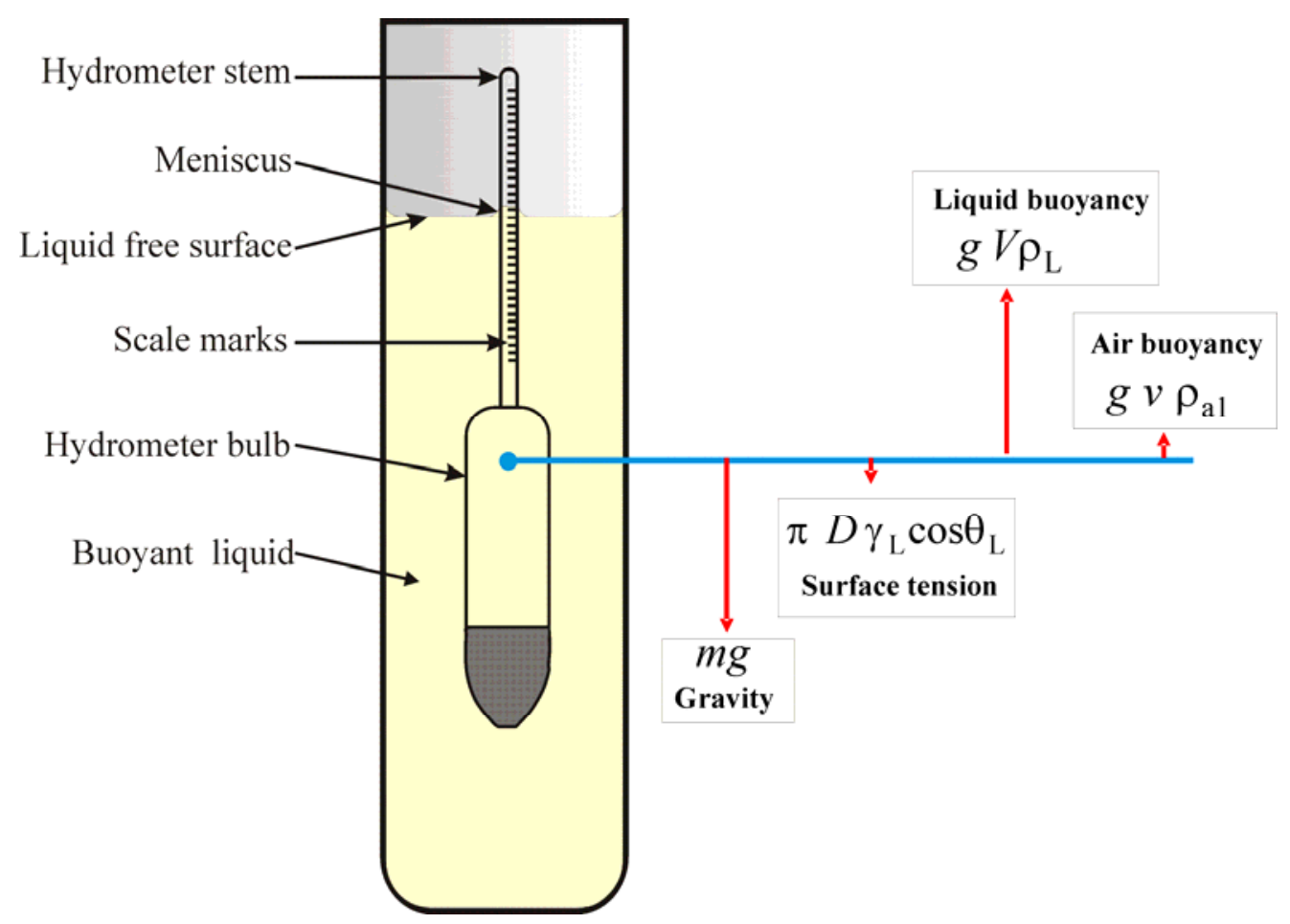

Figure A1. Schematic of a freely floating hydrometer with representations of the forces imposed on it.

Hence, while primarily a function of liquid density $\rho_{\mathrm{L}}$, hydrometer readings are also dependent on the liquid surface tension $\gamma_{\mathrm{L}}$ and the contact angle between the liquid surface and the hydrometer stem $\theta_{\mathrm{L}}$. Most liquids partially or completely wet clean glass. For such liquids, a curved liquid-vapor interface (meniscus) rises up the hydrometer stem and, in effect, pulls the hydrometer deeper into the liquid.

Expressed in units of density, the effect of surface tension on the reading of a hydrometer is:

$c_{\gamma}=\frac{\pi D \gamma_{\mathrm{L}} \cos \theta_{\mathrm{L}}}{g V} \cong \frac{\pi D \gamma_{\mathrm{L}} \rho_{\mathrm{mid}}}{g m}$

where $D$ is the hydrometer stem diameter, $V$ is the volume of the submerged portion of the hydrometer, $g$ is the gravitational constant, $\gamma_{\mathrm{L}}$ is the surface tension of the liquid being measured, and $\theta_{\mathrm{L}}$ is the contact angle of the liquid on the hydrometer stem (normally assumed to be zero). For most applications, the second, approximate expression in Equation 1 suffices: the contact angle is assumed to be zero and the submerged volume is approximated by the mass of the hydrometer $m$ divided by the density represented by the mid-range of the hydrometer 
scale, $\rho_{\text {mid }}$.

When aqueous solutions contact a clean, glass hydrometer, the rising meniscus can alter the hydrometer's equilibrium position by the equivalent of up to $0.2 \%$ reduction of the liquid density. For hydrocarbon liquids, the reduction of the apparent density can be as large as $0.1 \%$. To determine whether on not surface tension corrections are significant for a particular hydrometer application, we can use Equation A1 to calculate the effect of a 1 dyne/cm surface tension change. For a typical hydrometer (submerged volume $50 \mathrm{~cm}^{3}$, stem diameter $0.5 \mathrm{~cm}$ ), a 1 dyne $/ \mathrm{cm}$ surface tension change causes a reading change of $3.2 \times 10^{-5} \mathrm{~g} / \mathrm{cm}^{3}$. Aqueous solutions are particularly susceptible to surface tension changes due to contaminants. Distilled water has a surface tension of approximately $73 \mathrm{mN} / \mathrm{m}$ while distilled water contaminated with oil has a surface tension of approximately $60 \mathrm{mN} / \mathrm{m}$. Hence a hydrometer that was calibrated for distilled water will read high by $0.0004 \mathrm{~g} / \mathrm{cm}^{3}$ in water contaminated with oil. Distilled water contaminated with soap will have a surface tension of approximately $30 \mathrm{mN} / \mathrm{m}$ and a hydrometer calibrated for the surface tension of distilled water will read high by $0.0013 \mathrm{~g} / \mathrm{cm}^{3}$. These calculations assume that the contact angle is zero during hydrometer calibration and usage. If the contact angle is zero during calibration (well cleaned) and non-zero during usage (contaminated), the density errors will be worse than the estimates given above.

In the following case studies, the liquid density $\rho$ is the hydrometer reading $R$, plus a hydrometer correction $C$ :

$$
\rho=R+C=R+c_{\mathrm{s}}+c_{\gamma}
$$

As shown in Equation A2, the hydrometer correction can be broken into two parts. The quantity $c_{\mathrm{s}}$ is the scale correction, an offset due to vertical misplacement of the hydrometer scale within the stem. It would be the correction to the hydrometer for a liquid with zero surface tension. The quantity $c_{\gamma}$ is the portion of the hydrometer correction that can be attributed to surface tension effects as given in Equation A1.

The effects of surface tension for the following four cases will be covered:

1) hydrometer calibrated by hydrostatic weighing and used to measure a liquid density,

2) hydrometer calibrated in a liquid of known density and used to measure the density of a liquid with a different surface tension,

3) calibrations by the comparison method, and

4) hydrometer calibrated by the comparison method and used to measure the density of a liquid with a different surface tension.

Hydrometer Calibrated by Hydrostatic Weighing and Used to Measure a Liquid Density Calibration results from hydrostatic weighing (Cuckow's method ${ }^{3}$ ) are given as a correction to the hydrometer reading in the following form:

\footnotetext{
${ }^{3}$ Cuckow F W 1949 A New Method of High Accuracy for the Calibration of Reference Standard Hydrometers, J. Soc. Chem. Industry, 68, 44-9
} 


$$
C_{\mathrm{L}}=c_{\mathrm{s}}+B \gamma_{\mathrm{L}} \cos \theta_{\mathrm{L}}
$$

where $c_{\mathrm{s}}$ and $B$ are the calibration outputs, $\gamma_{\mathrm{L}}$ is the surface tension (in $\mathrm{mN} / \mathrm{m}$ ) and $\theta_{\mathrm{L}}$ is the contact angle for the liquid under test. $c_{\mathrm{s}}$ has the same units as the hydrometer scale and $B$ has the units of the hydrometer scale units divided by $\mathrm{mN} / \mathrm{m}$.

\section{Example A1:}

Given: A hydrometer is used in a liquid with surface tension of $26 \mathrm{mN} / \mathrm{m}$ and the reading is $1.025 \mathrm{~g} / \mathrm{cm}^{3}$. The values of $c_{s}$ and $B$ for the 1.025 position on the hydrometer are $0.0010 \mathrm{~g} / \mathrm{cm}^{3}$ and $3 \times 10^{-5}\left[\left(\mathrm{~g} / \mathrm{cm}^{3}\right) /(\mathrm{mN} / \mathrm{m})\right]$. What is the liquid density according to the hydrometer? Assume the hydrometer is well cleaned and that the contact angle is zero.

Solution: Using Equation A3, the hydrometer correction is:

$$
\begin{aligned}
& C_{\mathrm{L}}=c_{\mathrm{s}}+B \gamma_{\mathrm{L}} \cos \theta_{\mathrm{L}}=0.0010\left(\mathrm{~g} / \mathrm{cm}^{3}\right)+3 \times 10^{-5}\left[\left(\mathrm{~g} / \mathrm{cm}^{3} /(\text { dynes } / \mathrm{cm})\right] 26(\text { dynes } / \mathrm{cm}) \cos \left(0^{\circ}\right)\right. \\
& C_{\mathrm{L}}=0.0018\left(\mathrm{~g} / \mathrm{cm}^{3}\right), \text { and using Equation A2 }\left(C=C_{\mathrm{L}}\right), \text { the liquid density is: } \\
& \rho=R+C_{\mathrm{L}}=1.025\left(\mathrm{~g} / \mathrm{cm}^{3}\right)+0.0018\left(\mathrm{~g} / \mathrm{cm}^{3}\right)=1.0268\left(\mathrm{~g} / \mathrm{cm}^{3}\right)
\end{aligned}
$$

Hydrometer Calibrated in a Liquid of Known Density and Used to Measure the Density of a Liquid with a Different Surface Tension

A hydrometer can be calibrated by floating it in a reference liquid of known density, reading the hydrometer, and calculating the hydrometer correction using a rearranged version of Equation A2. One method of determining the reference liquid density is by Archimedes' principle using a sinker of known volume and mass. Alternatively, one could use literature density values for high purity liquids.

Surface tension affects the hydrometer reading during the calibration, but if the hydrometer is subsequently used to measure the density of liquid with the same surface tension, the hydrometer correction remains valid. However, if the hydrometer is used to measure the density of a liquid with a different surface tension, the change in a density measurement is:

$$
\Delta c_{\gamma}=\frac{\pi D}{g V}\left(\gamma_{\mathrm{L}}-\gamma_{\mathrm{R}}\right)
$$

where $\gamma_{L}$ is the surface tension of the liquid being measured, and $\gamma_{R}$ is the surface tension of the reference liquid used to calibrate the hydrometer. A contact angle of zero for both liquids is assumed in Equation A4. As given in Equation A1, a reasonable approximation to the submerged volume is the hydrometer mass divided by the liquid density represented by the mid-range of the hydrometer scale.

Once the change in surface tension correction $\Delta c_{\gamma}$ has been calculated, it is added to the hydrometer reading and the correction determined in the reference liquid to obtain the density of 
the liquid under test:

$$
\rho=R+C_{\mathrm{R}}+\Delta c_{\gamma}=R+\left(c_{\mathrm{s}}+c_{\gamma \mathrm{R}}\right)+\left(c_{\gamma \mathrm{L}}-c_{\gamma \mathrm{R}}\right)=R+c_{\mathrm{s}}+c_{\gamma \mathrm{L}}=R+C_{\mathrm{L}}
$$

Note that Equations A4 and A5 are in density units and for hydrometers with any units other than density (i.e. specific gravity, percent alcohol, API, Baumé), hydrometer readings and the change in surface tension correction must be put into consistent units before they can be added (see Example A2).

\section{Example A2:}

Given: A specific gravity $60 / 60^{\circ} \mathrm{F}$ hydrometer with a range of 0.95 to 1.0 was calibrated in distilled water and the hydrometer correction was found to be +0.0010 at a reading of 0.9995 . The hydrometer is subsequently used to measure the density of an oil and the hydrometer reading is also 0.9995 . The surface tensions of the water and of the oil are $75 \mathrm{mN} / \mathrm{m}$ and $25 \mathrm{mN} / \mathrm{m}$, respectively. The hydrometer weighs $50 \mathrm{~g}$ and its stem diameter is $0.5 \mathrm{~cm}$. What is the specific gravity of the oil?

Solution: Calculate an approximate submerged volume for the hydrometer using its mass, the mid-range of the hydrometer stem, and the density of water at $60{ }^{\circ} \mathrm{F}$ :

$$
V=\frac{m}{\rho_{\text {mid }}}=\frac{m}{\left(\operatorname{sp~gr~} 60 / 60_{\text {mid }}\right) \rho_{H 2 O}\left(60{ }^{\circ} \mathrm{F}\right)}=\frac{50 \mathrm{~g}}{0.975\left(0.999016 \mathrm{~g} / \mathrm{cm}^{3}\right)}=51.33 \mathrm{~cm}^{3}
$$

Use Equation A4 to determine the change in hydrometer reading (in density units) caused by the surface tension difference. Note that 1 dyne $/ \mathrm{cm} \equiv 1 \mathrm{~g} / \mathrm{s}^{2}$ :

$$
\Delta c_{\gamma}=\frac{\pi D}{g V}\left(\gamma_{\mathrm{L}}-\gamma_{\mathrm{R}}\right)=\frac{\pi(0.5 \mathrm{~cm})}{51.33 \mathrm{~cm}^{3}\left(980.665 \mathrm{~cm} / \mathrm{s}^{2}\right)}\left(25 \mathrm{~g} / \mathrm{s}^{2}-75 \mathrm{~g} / \mathrm{s}^{2}\right)=-0.0016 \mathrm{~g} / \mathrm{cm}^{3}
$$

Apply the hydrometer correction determined with the reference liquid $C_{\mathrm{R}}$ to the hydrometer reading $R$ and calculate the density represented by the mark, absent surface tension corrections:

$$
\rho_{\mathrm{R}+\mathrm{C}_{R}}=\rho_{\mathrm{H} 2 \mathrm{O}}\left(60{ }^{\circ} \mathrm{F}\right)\left(R+C_{\mathrm{R}}\right)=0.999016 \mathrm{~g} / \mathrm{cm}^{3}(0.9995+0.0010)=0.9995 \mathrm{~g} / \mathrm{cm}^{3}
$$

Calculate the corrected oil density using the surface tension correction:

$$
\rho=\rho_{\mathrm{R}+\mathrm{C}_{\mathrm{R}}}+\Delta c_{\gamma}=0.9995 \mathrm{~g} / \mathrm{cm}^{3}+\left(-0.0016 \mathrm{~g} / \mathrm{cm}^{3}\right)=0.9979 \mathrm{~g} / \mathrm{cm}^{3}
$$

Calculate the specific gravity of the oil:

$\operatorname{spgr} 60 / 60{ }^{\circ} \mathrm{F}=\frac{\rho}{\rho_{\mathrm{H} 2 \mathrm{O}}\left(60{ }^{\circ} \mathrm{F}\right)}=\frac{0.9979 \mathrm{~g} / \mathrm{cm}^{3}}{0.999016 \mathrm{~g} / \mathrm{cm}^{3}}=0.9989$

\section{Calibrations by the Comparison Method}


Hydrometers are often calibrated by comparing them to reference hydrometers floating in the same liquid. If the hydrometers have the same stem diameter and are well cleaned (i.e. same contact angle), the surface tension effects are the same for both hydrometers and surface tension corrections are unnecessary. However, it is important to note that it may be necessary to apply a surface tension correction to the reference hydrometer. For instance, if the correction for the reference hydrometer was determined using a liquid of one surface tension and then it was used in the comparison method in a liquid with a different surface tension, a procedure like that of Example A2 would be necessary to obtain correct measurements from the reference hydrometer. Similarly, the hydrometer correction determined by the comparison method for the hydrometer under test is valid if it is subsequently used in a liquid with the same surface tension, but if different liquids are used during calibration and subsequent usage, surface tension corrections based on Equation A4 are necessary (see Example A4). Hence, the surface tension of the liquids used during calibrations performed by the comparison method should be specified so that surface tension corrections can be made when the hydrometer under test is used later.

Hydrometer Calibrated by the Comparison Method and Used to Measure the Density of a Liquid with a Different Surface Tension

In this circumstance it is necessary to know the surface tension of the liquid used to determine the hydrometer correction, the surface tension of the liquid that is being tested, the hydrometer mass, and the stem diameter. Equation A4 gives the effect of surface tension on the hydrometer reading in units of density. As for Example A2, if the hydrometer units are something other than density units (i.e. specific gravity, percent alcohol, API gravity), hydrometer readings and the change in surface tension correction must be put into consistent units before they can be added.

\section{Example A3:}

Given: A 1.0000 to $1.0500 \mathrm{sp}$ gr $60 / 60^{\circ} \mathrm{F}$ hydrometer was calibrated by the comparison method and at a reading of 1.0350 its correction is -0.0008 . The surface tension of the liquid used during calibration was $68 \mathrm{mN} / \mathrm{m}$. The hydrometer mass is $50 \mathrm{~g}$ and its stem diameter is $0.5 \mathrm{~cm}$. The hydrometer is being used to measure the density of a liquid with a surface tension of $33 \mathrm{mN} / \mathrm{m}$ and the reading of the hydrometer in the liquid under test is 1.0350 . What is the specific gravity of the liquid under test?

Solution: Using the same approach shown in Example A2, the approximate submerged volume of the hydrometer is:

$$
V=\frac{m}{\rho_{\text {mid }}}=\frac{m}{\left(\operatorname{sp~gr~} 60 / 60{ }^{\circ} \mathrm{F}_{\text {mid }}\right) \rho_{\mathrm{H} 2 \mathrm{O}}\left(60{ }^{\circ} \mathrm{F}\right)}=\frac{50 \mathrm{~g}}{1.025\left(0.999016 \mathrm{~g} / \mathrm{cm}^{3}\right)}=48.83 \mathrm{~cm}^{3}
$$

Using Equation A4, the change in surface tension correction is:

$$
\Delta c_{\gamma}=\frac{\pi D}{g V}\left(\gamma_{\mathrm{L}}-\gamma_{\mathrm{R}}\right)=\frac{\pi(0.5 \mathrm{~cm})}{48.83 \mathrm{~cm}^{3}\left(980.665 \mathrm{~cm} / \mathrm{s}^{2}\right)}\left(33 \mathrm{~g} / \mathrm{s}^{2}-68 \mathrm{~g} / \mathrm{s}^{2}\right)=-0.0011 \mathrm{~g} / \mathrm{cm}^{3}
$$

Apply the hydrometer correction $\left(C_{\mathrm{R}}\right)$ to the hydrometer reading $(R)$ measured in the liquid under test and calculate the density represented by the mark, absent surface tension corrections: 


$$
\rho_{\mathrm{R}+\mathrm{C}_{\mathrm{R}}}=\rho_{\mathrm{H} 2 \mathrm{O}}\left(60{ }^{\circ} \mathrm{F}\right)\left(R+C_{\mathrm{R}}\right)=0.999016 \mathrm{~g} / \mathrm{cm}^{3}(1.0350-0.0008)=1.0332 \mathrm{~g} / \mathrm{cm}^{3}
$$

Calculate the corrected density for the liquid under test using the surface tension correction:

$$
\rho=\rho_{\mathrm{R}+\mathrm{C}_{\mathrm{R}}}+\Delta c_{\gamma}=1.0332 \mathrm{~g} / \mathrm{cm}^{3}+\left(-0.0011 \mathrm{~g} / \mathrm{cm}^{3}\right)=1.0321 \mathrm{~g} / \mathrm{cm}^{3}
$$

Calculate the specific gravity of the liquid under test:

$$
\text { sp gr } 60 / 60{ }^{\circ} \mathrm{F}=\frac{\rho}{\rho_{\text {Н } 2}\left(60{ }^{\circ} \mathrm{F}\right)}=\frac{1.0321 \mathrm{~g} / \mathrm{cm}^{3}}{0.999016 \mathrm{~g} / \mathrm{cm}^{3}}=1.0331
$$

\section{Appendix B: Corrections to Hydrometers for Temperature Effects}

Liquid temperature can affect hydrometer density measurements in two ways: 1) thermal expansion for the hydrometer material (generally glass) and 2) thermal expansion of the liquid under test. Hydrometers that read in density units need only be corrected for the volumetric thermal expansion of the hydrometer glass $(\beta)$, nominally 26 parts in $10^{6}$ for each $1{ }^{\circ} \mathrm{C}$ temperature change. But consider a specific gravity hydrometer labeled with the sp gr $60 / 60^{\circ} \mathrm{F}$ unit. This hydrometer is designed to give the density of the liquid under test at $60^{\circ} \mathrm{F}$ relative to the density of water at $60^{\circ} \mathrm{F}$. Instructions for using such a hydrometer call for the liquid and the hydrometer to be uniformly at $60^{\circ} \mathrm{F}$ during the measurement. If the liquid under test is not actually at $60^{\circ} \mathrm{F}$, corrections for thermal expansion of the hydrometer glass and of the liquid are necessary to obtain specific gravity at the reference temperature conditions. This is also true for API and Baumé hydrometers. The volumetric thermal expansion coefficient for the liquid must be known for the particular liquid under test. Volumetric expansion coefficients for common liquids are: water and aqueous solutions $\approx 200 \times 10^{-6} /{ }^{\circ} \mathrm{C}$, oils $\approx 800 \times 10^{-6} /{ }^{\circ} \mathrm{C}$, so temperature corrections due to the liquid are normally much more significant than those for the glass.

\section{Temperature Corrections for Density Hydrometers}

The corrections to be applied to a hydrometer, when used at temperatures other than its standard temperature, may be obtained as follows. Assume $R$ to be the reading of a density hydrometer indicating density correctly when floating in a liquid at temperature $T_{0}$, the standard temperature for the instrument. Then

$$
m=R V
$$

where $m$ is the mass of the hydrometer and $V$ is the submerged volume of the hydrometer.

Now assume the hydrometer to be again reading $R$, while floating in a liquid at temperature $T^{\prime}$. Let $c_{\mathrm{T}^{\prime}}$ be the correction which must be added to $R$ in order to give the density of the second liquid in $\mathrm{g} / \mathrm{cm}^{3}$ at $T^{\prime}$. In this case, we have:

$$
m=\left(R+c_{\mathrm{T}^{\prime}}\right) V\left\lfloor 1+\beta_{\mathrm{g}}\left(T^{\prime}-T_{0}\right)\right\rfloor
$$


where $\beta_{\mathrm{g}}$ is the volumetric thermal expansion coefficient of the glass of which the hydrometer is made.

Solving Equations B1 and B2 for $c_{\mathrm{T}^{\prime}}$, we obtain:

$$
c_{\mathrm{T}^{\prime}}=-\frac{R \beta_{\mathrm{g}}\left(T^{\prime}-T_{0}\right)}{1+\beta_{\mathrm{g}}\left(T^{\prime}-T_{0}\right)} .
$$

Since $\beta_{\mathrm{g}}$ is small compared to 1 , we may write:

$c_{\mathrm{T}^{\prime}} \cong-R \beta_{\mathrm{g}}\left(T^{\prime}-T_{0}\right)$

\section{Example B1:}

Given: A density hydrometer with reference temperature of $20^{\circ} \mathrm{C}$ is used to determine the density of a liquid at $30^{\circ} \mathrm{C}$. The hydrometer reads $1.0000 \mathrm{~g} / \mathrm{cm}^{3}$ and the volumetric thermal expansion coefficient for the hydrometer glass is $26 \times 10^{-6} /{ }^{\circ} \mathrm{C}$. What is the density of the liquid?

Solution: Calculate the correction using Equation B4:

$$
c_{\mathrm{T}^{\prime}}=-R \beta_{\mathrm{g}}\left(T^{\prime}-T_{0}\right)=-1 \mathrm{~g} / \mathrm{cm}^{3}\left(26 \times 10^{-6} /{ }^{\circ} \mathrm{C}\right)\left(30{ }^{\circ} \mathrm{C}-20{ }^{\circ} \mathrm{C}\right)=-0.0003 \mathrm{~g} / \mathrm{cm}^{3}
$$

Add the correction to the reading to obtain the liquid density:

$$
\rho=R+c_{\mathrm{T}^{\prime}}=1.0000 \mathrm{~g} / \mathrm{cm}^{3}-0.0003 \mathrm{~g} / \mathrm{cm}^{3}=0.9997 \mathrm{~g} / \mathrm{cm}^{3}
$$

Note that this is the density of the liquid at $30^{\circ} \mathrm{C}$, not its density at $20^{\circ} \mathrm{C}$.

Temperature Corrections for Specific Gravity Hydrometers

The temperature correction for specific gravity hydrometers is obtained as follows._Assume $S$ to be the reading of a hydrometer indicating specific gravity correctly at $T_{0}{ }^{\circ} \mathrm{C}$ relative to the density of water at $T_{0}{ }^{\circ} \mathrm{C}$ (a sp gr $T_{0} / T_{0}$ hydrometer). Then

$$
m=V \rho_{\mathrm{L}}\left(T_{0}\right)=V S \rho_{\mathrm{H} 2 \mathrm{O}}\left(T_{0}\right)
$$

where $m$ is the mass of the hydrometer, $V$ is the submerged volume of the hydrometer, $\rho_{\mathrm{L}}\left(T_{0}\right)$ is the density of the liquid under test at $T_{0}$, and $\rho_{\mathrm{H} 2 \mathrm{O}}\left(T_{0}\right)$ is the density of water at $T_{0}$.

Now assume the hydrometer is placed in a liquid at $T^{\prime}$ such that the instrument again reads $S$. Let $c_{\mathrm{T}^{\prime}}$ be the correction added to $S$ to give the correct $\mathrm{sp}$ gr $\mathrm{T}_{0} / \mathrm{T}_{0}$ for the liquid, then:

$$
m=\left(S+c_{\mathrm{T}^{\prime}}\right) V\left[1+\beta_{\mathrm{g}}\left(T^{\prime}-T_{0}\right)\right] \rho_{\mathrm{H} 2 \mathrm{O}}\left(T_{0}\right)\left[1+\beta_{\mathrm{L}}\left(T^{\prime}-T_{0}\right)\right]
$$


where $\beta_{\mathrm{L}}$ is the volumetric thermal expansion coefficient of the liquid under test. In Equation B6, we have used the definition of $\mathrm{sp}$ gr $60 / 60^{\circ} \mathrm{F}$ for the corrected hydrometer reading: $\left(S+c_{\mathrm{T}^{\prime}}\right)=\rho_{\mathrm{L}}\left(T_{0}\right) / \rho_{\mathrm{H} 2 \mathrm{O}}\left(T_{0}\right)$.

Solving Equations B5 and B6 for $c_{\mathrm{T}^{\prime}}$, we obtain:

$c_{\mathrm{T}^{\prime}}=S\left[\frac{1-\left[1+\beta_{\mathrm{L}}\left(T^{\prime}-T_{0}\right)\right]\left[1+\beta_{\mathrm{g}}\left(T^{\prime}-T_{0}\right)\right]}{\left[1+\beta_{\mathrm{L}}\left(T^{\prime}-T_{0}\right)\right]\left[1+\beta_{\mathrm{g}}\left(T^{\prime}-T_{0}\right)\right]}\right]$,

from which it is clear that the expansion of the liquid as well as the expansion of the hydrometer glass must be taken into account. Neglecting second order terms, Equation B7 can be simplified to:

$$
c_{\mathrm{T}^{\prime}} \cong-S\left(T^{\prime}-T_{0}\right)\left(\beta_{\mathrm{L}}+\beta_{\mathrm{g}}\right)
$$

Example B2:

Given: A specific gravity $60 / 60$ hydrometer is used to measure the density of an oil sample that is at $25^{\circ} \mathrm{C}$ and it reads 0.7800 . The volumetric thermal expansion coefficient of the oil is known to be $900 \times 10^{-6} /{ }^{\circ} \mathrm{C}$ and the volumetric thermal expansion coefficient for the hydrometer glass is $26 \times 10^{-6} /{ }^{\circ} \mathrm{C}$. What is the sp gr $60 / 60$ of the oil? Assume that surface tension effects are already accounted for in the 0.7800 reading.

Solution: Use Equation B8 to calculate the temperature correction for the hydrometer:

$$
c_{\mathrm{T}^{\prime}}=-S\left(T^{\prime}-T_{0}\right)\left(\beta_{\mathrm{L}}+\beta_{\mathrm{g}}\right)=-0.7800\left(25^{\circ} \mathrm{C}-15.56^{\circ} \mathrm{C}\right)\left(900 \times 10^{-6} /{ }^{\circ} \mathrm{C}+26 \times 10^{-6} /{ }^{\circ} \mathrm{C}\right)=-0.0068
$$

$\operatorname{sp} \operatorname{gr} 60 / 60{ }^{\circ} \mathrm{F}=S+c_{\mathrm{T}^{\prime}}=0.7800+(-0.0068)=0.7732$

The correction of Equation B8 can be applied to other hydrometer scales that are functions of specific gravity $T_{0} / T_{0}$ scales by converting them to specific gravity, making the necessary temperature corrections, and then returning them to the original scale.

\section{Example B3:}

Given: An API gravity hydrometer reads 45.40 when floated in oil at $22{ }^{\circ} \mathrm{C}$. The volumetric thermal expansion coefficient of the oil is known to be $800 \times 10^{-6} /{ }^{\circ} \mathrm{C}$ and the volumetric thermal expansion coefficient for the hydrometer glass is $26 \times 10^{-6} /{ }^{\circ} \mathrm{C}$. What is the temperature corrected API gravity of the oil? Assume that surface tension effects are already accounted for in the 45.40 reading.

Solution: First use the rearranged definition of API gravity to obtain the uncorrected sp gr 60/60 ${ }^{\circ} \mathrm{F}$ reading for the oil: 
sp gr $60 / 60{ }^{\circ} \mathrm{F}=\frac{141.5}{\text { API Gravity, deg }+131.5}=\frac{141.5}{45.4+131.5}=0.7999$.

Calculate the temperature correction and the corrected specific gravity:

$c_{\mathrm{T}^{\prime}}=-S\left(T^{\prime}-T_{0}\right)\left(\beta_{\mathrm{L}}+\beta_{\mathrm{g}}\right)=-0.7999\left(22^{\circ} \mathrm{C}-15.56^{\circ} \mathrm{C}\right)\left(800 \times 10^{-6} /{ }^{\circ} \mathrm{C}+26 \times 10^{-6} /{ }^{\circ} \mathrm{C}\right)=-0.0043$

$\operatorname{sp} \operatorname{gr} 60 / 60{ }^{\circ} \mathrm{F}=S+c_{\mathrm{T}^{\prime}}=0.7999+(-0.0043)=0.7956$.

Convert the corrected specific gravity back to API gravity:

API Gravity, deg $=\frac{141.5}{\operatorname{sp~gr~} 60 / 60{ }^{\circ} \mathrm{F}}-131.5=\frac{141.5}{0.7956}-131.5=46.35$ 


\section{Appendix C. Conversion of Liquid Density to Other Hydrometer Scales [7, 4]}

Hydrometers calibrated in degrees Baumé at $20^{\circ} \mathrm{C}$ are used to determine the percentage of cane sugar by weight in solution. The scale is defined by

degrees Baumé at $20{ }^{\circ} \mathrm{C}=145-145 /\left(\right.$ specific gravity $\left.20{ }^{\circ} \mathrm{C} / 20{ }^{\circ} \mathrm{C}\right)$.

Expressed in terms of density, $\rho\left(\mathrm{g} / \mathrm{cm}^{3}\right)$, the scale is defined by degrees Baumé at $20^{\circ} \mathrm{C}=145-145 /\left[\rho\left(20^{\circ} \mathrm{C}\right) / 0.998206 \mathrm{~g} / \mathrm{cm}^{3}\right]$.

The scale for indicating degrees Baumé of liquids lighter than water is defined by

$$
\text { degrees Baumé }=140 /\left(\text { specific gravity } 60^{\circ} \mathrm{F} / 60{ }^{\circ} \mathrm{F}\right)-130 \text {. }
$$

Expressed in terms of density, $\rho$, the scale is defined by

$$
\text { degrees Baumé }=140 /\left[\rho\left(60^{\circ} \mathrm{F}\right) / 0.999016 \mathrm{~g} / \mathrm{cm}^{3}\right]-130 \text {. }
$$

The scale indicating degrees Baumé for liquids heavier than water is defined by

$$
\text { degrees Baumé }=145-145 /\left(\text { specific gravity } 60{ }^{\circ} \mathrm{F} / 60{ }^{\circ} \mathrm{F}\right) \text {. }
$$

Expressed in terms of density, $\rho$, the scale is defined by

$$
\text { degrees Baumé }=145-145 /\left[\rho\left(60{ }^{\circ} \mathrm{F}\right) / 0.999016 \mathrm{~g} / \mathrm{cm}^{3}\right] \text {. }
$$

The hydrometers in general use in the petroleum industry in the United States are based on the American Petroleum Institute (API) scale. The relationship between specific gravity and the API scale is

$$
\text { degrees API }=141.5 /\left(\text { specific gravity } 60^{\circ} \mathrm{F} / 60^{\circ} \mathrm{F}\right)-131.5 \text {. }
$$

Expressed in terms of density, $\rho$, the scale is defined by

$$
\text { degrees API }=141.5 /\left[\rho\left(60{ }^{\circ} \mathrm{F}\right) / 0.999016 \mathrm{~g} / \mathrm{cm}^{3}\right]-131.5 \text {. }
$$

[4] Standard Density and Volumetric Tables, NBS Circular 19, U.S. Government Printing Office, Washington D.C., 1924. 


\section{Appendix D. Nomenclature}

\begin{tabular}{|c|c|}
\hline$C$ & hydrometer correction, $=c_{\mathrm{s}}+c_{\gamma}$ \\
\hline$C_{\mathrm{R}}$ & hydrometer correction for a reference liquid $\mathrm{R}$ \\
\hline$C_{\mathrm{L}}$ & hydrometer correction for a particular liquid under test L \\
\hline$c_{\mathrm{s}}$ & scale correction \\
\hline$c_{\gamma}$ & surface tension correction \\
\hline$c_{\gamma \mathrm{R}}$ & surface tension correction for a reference liquid \\
\hline$c_{\gamma \mathrm{L}}$ & surface tension correction for a particular liquid under test \\
\hline$\Delta c_{\gamma}$ & change in surface tension correction between two liquids, $=c_{\gamma \mathrm{L}}-c_{\gamma \mathrm{R}}$ \\
\hline$c_{\mathrm{T}^{\prime}}$ & hydrometer correction for temperature effects \\
\hline$B$ & coefficient for surface tension correction from Cuckow's method \\
\hline$D$ & hydrometer stem diameter \\
\hline$g$ & gravitational constant, $=980.665 \mathrm{~cm} / \mathrm{s}^{2}$ \\
\hline$m$ & mass of a hydrometer \\
\hline$R$ & density hydrometer reading \\
\hline$S$ & specific gravity hydrometer reading \\
\hline sp gr 60/ & specific gravity hydrometer scale, $=\rho_{\mathrm{L}}\left(60^{\circ} \mathrm{F}\right) / \rho_{\mathrm{H} 2 \mathrm{O}}\left(60^{\circ} \mathrm{F}\right)$ \\
\hline$T$ & temperature \\
\hline$T_{0}$ & reference temperature \\
\hline$T^{\prime}$ & temperature at which a hydrometer measurement is performed \\
\hline$V$ & submerged volume of a hydrometer \\
\hline$v$ & volume of the hydrometer stem above the liquid surface \\
\hline$V_{\mathrm{R}}$ & submerged volume for a reference hydrometer \\
\hline$\beta_{\mathrm{g}}$ & volumetric thermal expansion coefficient for glass \\
\hline$\beta_{\mathrm{L}}$ & volumetric thermal expansion coefficient for liquid under test $\mathrm{L}$ \\
\hline$\gamma_{\mathrm{L}}$ & surface tension for liquid under test $\mathrm{L}$ \\
\hline$\gamma_{\mathrm{R}}$ & surface tension for reference liquid $\mathrm{R}$ \\
\hline$\rho$ & density \\
\hline$\rho_{\mathrm{a} 1}$ & density of air surrounding stem \\
\hline$\rho_{\mathrm{L}}$ & density of a liquid under test $\mathrm{L}$ \\
\hline$\rho_{\mathrm{R}}$ & density of a reference liquid $\mathrm{R}$ \\
\hline$\rho_{\mathrm{H} 2 \mathrm{O}}(T)$ & density of water at temperature $T, \rho_{\mathrm{H} 2 \mathrm{O}}\left(60{ }^{\circ} \mathrm{F}\right)=0.999016 \mathrm{~g} / \mathrm{cm}^{3}$ \\
\hline$\rho_{\text {mid }}$ & density represented by the middle of the hydrometer range \\
\hline$\rho_{\mathrm{R}+\mathrm{C}_{\mathrm{R}}}$ & ensity according to a reference hydrometer, without surface tension correction \\
\hline$\theta_{\mathrm{L}}$ & contact angle for liquid under test $\mathrm{L}$ \\
\hline
\end{tabular}




\title{
REPORT OF CALIBRATION
}

FOR A

\section{HYDROMETER}

\author{
May 18, 2007 \\ Maker: Hydrometer Co. \\ Indication: Specific Gravity 60/60 \\ Hydrometer Scale: 0.850 to 0.875 \\ submitted by \\ Hydrometer User Co. \\ 124 Water Way \\ Gaithersburg, MD 20899
}

Serial No.: 123456

(Purchase Order Number 3456, dated April 17, 2007)

The hydrometer identified above was calibrated by hydrostatic weighing (Cuckow's method) ${ }^{1}$ at three stem scale marks at approximately $10 \%, 50 \%$, and $90 \%$ of the hydrometer range. The calibration method requires weighing the hydrometer in air and while the hydrometer is suspended at the stem scale mark to be calibrated in a liquid of known density and surface tension. These data were used to calculate the density of the liquid (with zero surface tension) that would freely float the hydrometer at the calibrated stem scale marks. The Cuckow's method density measurements were converted to the units displayed on the hydrometer under test (specific gravity $60 / 60$ ) by dividing by the density of water at 60 ${ }^{\circ} \mathrm{F}\left(0.999016 \mathrm{~g} / \mathrm{cm}^{3}\right)$.

The NIST calibration results are given as a correction to the hydrometer reading in the following form:

$C_{\mathrm{L}}=A+B \gamma_{\mathrm{L}} \cos \theta_{\mathrm{L}}$

where $C_{\mathrm{L}}$ is the correction (for the customer's liquid, $\mathrm{L}$ ) to be added to the hydrometer reading, $A$ and $B$ are calibration constants, $\gamma_{L}$ is the surface tension of the customer's liquid (in dynes $/ \mathrm{cm}$ ), and $\theta_{L}$ is the contact angle of the customer's liquid on the hydrometer stem (normally assumed to be zero). The quantity $A$ is the correction to the hydrometer for a liquid with zero surface tension and $A$ has the same units as the hydrometer scale. The second term in Equation (1) corrects for the effects of hydrometer and liquid surface interactions and $B$ has the units of the hydrometer scale units divided by dynes $/ \mathrm{cm}$. Typically, ignoring the second term will affect density measurements by about $0.2 \%$ for aqueous solutions and about $0.1 \%$ for hydrocarbon liquids. Table 1 lists the calibrated hydrometer marks, the values of $A$ and $B$ at each calibrated mark, the uncertainty of the density measurements made at NIST, and example hydrometer corrections from Equation (1) assuming a customer surface tension of 25 dynes $/ \mathrm{cm}$ and a contact angle of zero.

Table 1. Calibration results and example correction values for $\gamma_{\mathrm{L}}=25 \mathrm{dynes} / \mathrm{cm}$.

${ }^{1}$ Aguilera, J., Wright, J., and Bean, V., Hydrometer Calibration by Hydrostatic Weighing with Automated Liquid Surface Positioning, Meas. Sci. Technol. 19 (2008) 015104. 


\begin{tabular}{ccccc}
\hline Calibrated Mark & $\boldsymbol{A}$ & $\boldsymbol{B}$ & $\begin{array}{c}\text { Expanded Uncertainty }{ }^{2} \\
\left(\text { parts in } 10^{6}\right)\end{array}$ & Example $\boldsymbol{C}_{\mathrm{L}}$ \\
\hline 0.8530 & -0.00065 & $1.765 \mathrm{E}-05$ & 100 & -0.00020 \\
0.8630 & -0.00049 & $1.784 \mathrm{E}-05$ & 100 & -0.00005 \\
0.8730 & -0.00068 & $1.807 \mathrm{E}-05$ & 100 & -0.00023 \\
\hline
\end{tabular}

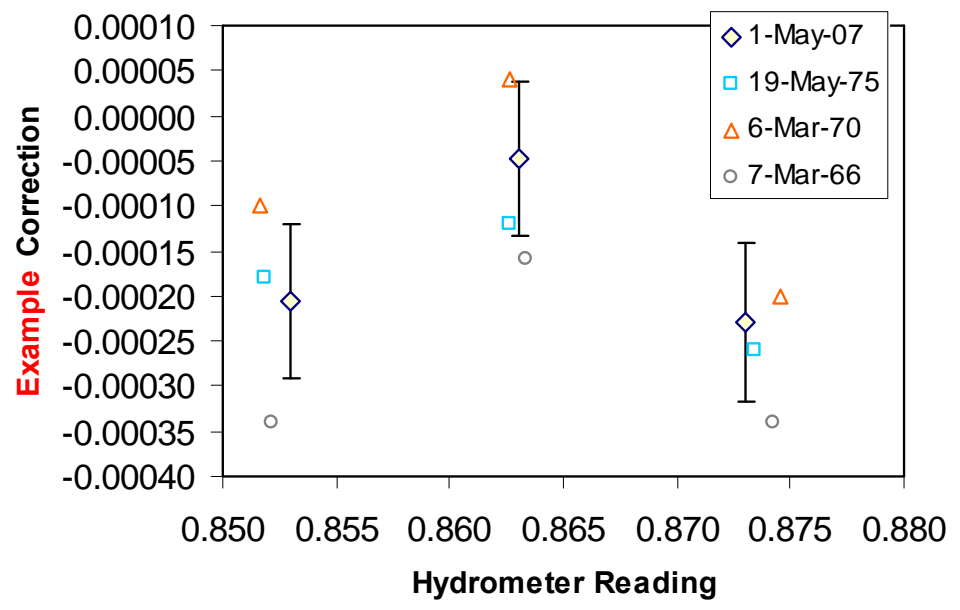

Figure 1. Example hydrometer corrections along with the results of prior NIST calibrations (if available)

The uncertainty of the results from the Cuckow's method apparatus includes type B components related to balance measurements, the density and surface tension of the liquid used in the apparatus, the ability to align the hydrometer mark with the liquid surface, and the thermal expansion coefficient for the hydrometer glass. Type A uncertainty is assessed from five repeated measurements made at the each calibrated mark.

When the hydrometer is applied by the customer to measure the density of a liquid, uncertainties beyond the NIST calibration must be considered. These uncertainty components include: the surface tension of the liquid under test, the cleanliness of the hydrometer stem and its effect on the contact angle of the liquid with the hydrometer stem, thermometer calibration, and temperature non-uniformity of the liquid sample. When these uncertainty components are considered, the uncertainty of the liquid density measurement made with the hydrometer can be 400 parts in $10^{6}$ or larger. $^{1}$

For the Director,

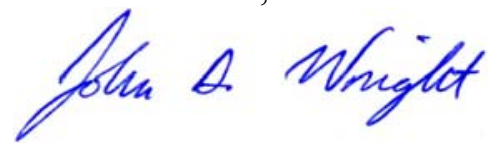

Dr. John D. Wright

Project Leader, Fluid Metrology Group

Process Measurements Division

Chemical Science and Technology Laboratory

National Institute of Standards and Technology

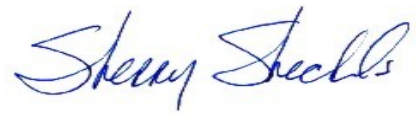

Sherry Sheckels

Calibration Technician, Fluid Metrology Group

Process Measurements Division

Chemical Science and Technology Laboratory

National Institute of Standards and Technology

2 Approximately $95 \%$ confidence level $(k=2)$, see Taylor, B. N. and Kuyatt, C. E., Guidelines for Evaluating and Expressing the Uncertainty of NIST Measurement Results, NIST Technical Note 1297, NIST (January, 1993). 